\title{
ANTECEDENTES ECLESIOLÓGICOS DE G. B. MONTINI - SAN PABLO VI. A PROPÓSITO DE SU RECIENTE CANONIZACIÓN
}

Fecha de recepción: 4 de febrero de 2019

Fecha de aceptación y versión final: 24 de abril de 2019

RESUMEN: Un aspecto quizá poco conocido del recientemente canonizado papa Pablo VI es que, incluso antes de ser elegido Sumo Pontífice, era un experto estudioso de la Iglesia, a la que dedicó varios de sus escritos. Se analizan en este artículo las características más importantes de su aproximación eclesiológica, centrando la atención en los años de su ministerio episcopal en Milán. Para ello se pasa revista a su formación humanística, filosófica y teológica, así como a los autores más relevantes que marcaron su perspectiva eclesiológica. Se ofrece asimismo una mirada sintética de los principales textos en los que abordó el misterio de la Iglesia.

PALABRAS CLAVE: Iglesia; G. B. Montini; san Pablo VI; siglo XX; arzobispo de Milán.

\section{Ecclesiological Background of G. B. Montini - Saint Paul VI. On the Occasion of his Recent Canonization}

ABSTRACT: A perhaps little-known aspect of the recently canonized Pope Paul VI is that, even before being elected Supreme Pontiff, he was an expert scholar of the Church, to whom he dedicated several of his writings. The most important characteristics of his ecclesiological approach are analyzed in this article, focusing attention on the years of his episcopal ministry in Milan. For this, his humanistic, philosophical and theological education is reviewed, as well as the most relevant authors who marked his ecclesiological perspective. It also offers a synthetic view of the main texts in which he addressed the mystery of the Church.

KEY WORDS: Church; G. B. Montini; Saint Paul VI; $20^{\text {th }}$ century; Archbishop of Milan.

* Universidad Peruana de Ciencias Aplicadas (UPC): k.berckh@gmail.com. 


\section{INTRODUCCIÓN}

La reciente canonización del papa Pablo VI ha sido ocasión para que muchos vuelvan los ojos hacia la vida y el ministerio de quien fuera Pastor de la Iglesia universal en una época tan trascendente para la comunidad eclesial: la celebración de la segunda parte del Concilio Vaticano II y los años medulares de su posterior aplicación. Particular atención han merecido sus encíclicas Populorum progressio y Humanae vitae, de las que paralelamente se han celebrado los quincuagésimos aniversarios de su publicación. Pero quizá para algunos haya pasado un tanto desapercibido que Giovanni Battista Montini fue también «uno de los grandes especialistas en temas eclesiales que ha conocido nuestro tiempo ${ }^{1}, \mathrm{y}$ que uno de sus documentos más significativos - pero que, curiosamente, ha quedado un tanto relegado en los anales de la historia- haya sido su encíclica programática Ecclesiam Suam, dedicada precisamente a la Iglesia.

El propósito de este artículo es revisar los rasgos más significativos de la aproximación eclesiológica de G. B. Montini - san Pablo VI, teniendo a la vista sus escritos previos a la elección pontificia. Para ello haremos preliminarmente un repaso de su formación humanística, filosófica y teológica - deteniéndonos de manera particular en los autores más representativos que aportaron en su perspectiva eclesiológica- y una mirada a sus principales escritos dedicados a la Iglesia ${ }^{2}$.

${ }^{1}$ C. Calderón, "Semblanza de Pablo VI", en Instituto Social León XIII, El diálogo según la mente de Pablo VI (Madrid: BAC, 1965), 93.

2 Como fuentes de los textos citaremos sobre todo las recopilaciones que en su momento publicó el Arzobispado de Milán: G. B. Montini, Discorsi su La Chiesa (1957-1962) (Milano: 1962) [DsC]; Roma e il Concilio - Lettere dal Concilio (Milano: 1963) [RC-LC]; Discorsi su la Madonna e su i Santi (1955-1962) (Milano: 1965) [DsMS]; los volúmenes promovidos por el «Istituto Paolo VI» de Brescia: G. B. Montini, Discorsi e scritti sul Concilio (1959-1963) (Brescia: 1983) [DsCon]; Lettere ai familiari. 1919-1943, I-II (Brescia: 1986) [LetFam]; Scritti fucini (1925-1933) (Brescia: 2004) [SF]; o algunas ediciones que de esos textos aparecieron en castellano: G. B. Montini, La amistad con Dios. Meditaciones inéditas de G. B. Montini (Madrid: San Pablo, 2008) $[A C D]$. Una referencia fundamental en este periodo es la edición crítica en cuatro volúmenes de G. B. Montini, Discorsi e scritti milanesi (1954-1963), I. 19541957. II. 1958-1960. III. 1961-1963. IV. Appendice e Indici (Brescia: Istituto Paolo VI - Edizioni Studium, 1997-1998) [DSM]. 


\section{FORMACIÓN HUMANÍSTICA, FILOSÓFICA Y TEOLÓGICA}

El futuro Pablo VI nació en Concesio, cerca de Brescia, en la región italiana de Lombardía, el 26 de septiembre de $1897^{3}$. Hijo de Giorgio Montini (1860-1943), un importante abogado y político católico, y de Giuditta Alghisi (1874-1943), una mujer muy piadosa y de gran personalidad, desde su infancia recibió una cuidada formación humana y espiritual.

Desde 1903 asistió a la escuela elemental y media en el Instituto Cesare Arisi, en Brescia, regentado por la Compañía de Jesús, aunque debido a su débil salud durante largos periodos hubo de hacerlo como alumno externo. Allí recibió una educación escolar de impronta clásica y humanista, al tiempo que su formación religiosa se dio en el marco de las congregaciones Marianas. Esas mismas limitaciones de salud lo llevarían a terminar sus estudios escolares (licenza ginnasiale) en el gimnasio estatal de Chiari, una pequeña ciudad cercana a Brescia.

De trascendental importancia para su desarrollo humano y espiritual fue el contacto que entabló con el Oratorio Santa Maria della Pace, llevado por los religiosos filipenses. Allí conocería, entre otros, a los padres Giulio Bevilacqua (1881-1965) y Paolo Caresana (1882-1973), que tanta influencia tendrían en el joven Battista. Con ellos, además de recibir una intensa formación en la fe y cultivar una particular sensibilidad hacia la liturgia, llevó a cabo diversas obras de apostolado, catequesis y caridad, imbuido del espíritu de san Felipe Neri.

Luego de haber obtenido el bachillerato (licenza liceale) en el liceo clásico estatal Arnaldo de Brescia y de haber realizado un intenso proceso de discernimiento vocacional, el 20 de octubre de 1916 comenzó sus estudios en el seminario diocesano Sant'Angelo de Brescia. Nuevamente, sin embargo, debido a su salud quebradiza, se le autorizó hacerlo como alumno externo y vivir en casa de sus padres. Esta particular circunstancia le permitió añadir a sus cursos filosóficos y teológicos la

3 Mayores informaciones biográficas pueden encontrarse en C. Calderón, Montini, Papa (Salamanca: Ediciones Sígueme, 1963); E. de la Hera, La noche transfigurada. Biografía de Pablo VI (Madrid: BAC, 2002); G. Adornato, Pablo VI. El coraje de la modernidad (Madrid: San Pablo, 2010); X. Toscani, ed., Paolo VI. Una biografia (Brescia: Istituto Paolo VI - Edizioni Studium, 2014); L. Bressan y A. Maffeis, eds., Montini, Arcivescovo di Milano (Brescia: Istituto Paolo VI - Edizioni Studium, 2016). 
lectura de textos literarios y humanísticos — lo que no era usual en su tiempo-.

Desde sus primeros años llevó con mucha seriedad sus estudios, adquiriendo así una sólida formación. Su bagaje cultural fue amplio, comenzando por el arte , la historia $^{5}$ y la literatura - a la que en un momento incluso pensó dedicarse ${ }^{6}$ - y siguiendo con la filosofía y la teo$\operatorname{logía}^{7}$. A los autores tradicionales — como san Agustín o santo Tomás de Aquino, por ejemplo- aunó un vivo interés por las corrientes de su tiempo, con una marcada preferencia por la cultura francesa ${ }^{8}$. Así pues,

${ }^{4}$ Cf. G. B. Montini, "L'arte di Beuron", 1929, en SF, 257-261; "Su l'arte sacra futura”, 1931, en SF, 502-506; Istituto Paolo VI, Paul VI et l'art. Journée d'études (Paris 27 janvier 1988) (Brescia: Edizioni Studium, 1989); Paolo VI, Su l'arte e agli artisti. Discorsi, messaggi e scritti (1963-1978) (Brescia: Istituto Paolo VI - Edizioni Studium, 2000).

5 El recién ordenado sacerdote Montini comparte con sus familiares en una carta: «Había acariciado la idea de volcarme hacia el estudio de la historia, y me encuentro ante los libros de filosofía y de latín» (G. B. Montini, Lettere a casa. 1915-1943 [Milano: Rusconi, 1987], n. 28, 13/1/1921, p. 57). Cf. G. B. Montini, "Per lo studio della storia cristiana", 1929, en SF, 345-351; id., Note scolastiche per la storia della diplomazia pontificia (Roma: Editrice Studium, 1934); R. Rossi, “G. B. Montini alla 'Sapienza'. Note di storia religiosa del Risorgimento”, Notiziario dell'Istituto Paolo VI 41 (2001): 7-29 (en las pp. 18-29 aparece la transcripción de unas notas autógrafas de G. B. Montini); A. Marchetto, "Fu monsignor Giovanni Battista Montini uno storico?", Apollinaris 62 (1989): 243-252; G. Rumi, "Il senso della storia in Paolo VI", en Istituto Paolo VI, Educazione, intellettuali e società in G. B. Montini-Paolo VI (Brescia: Studium, 1992), 118-129; F. Molinari, "Le letture del giovane Montini (Storia della Chiesa e dintorni)", en G. Campanini, et al., G. B. Montini e la società italiana, 1919-1939 (Brescia: CeDoc, 1983), 59-82.

${ }^{6}$ Así lo dice el propio G. B. Montini en una conferencia que pronunció en 1951: «Pensaba entonces [hacia el otoño de 1920] dedicarme a otros estudios especulativos o literarios» (G. B. Montini, "Discorso in occasione del $250^{\circ}$ anniversario della Pontificia Accademia Ecclesiastica”, 25/4/1951, en La Pontificia Accademia Ecclesiastica, 1701-1951 [Città del Vaticano: Tipografia Poliglota Vaticana, 1951], p. XV). Cf. también F. Lanza, "Paolo VI e la letteratura", Otto/Novecento 1 (1979): 5-42; ensayo más tarde ampliado por el mismo autor en Paolo VI e gli scrittori (Brescia: Istituto Paolo VI - Edizioni Studium, 1994).

${ }^{7}$ Confirmando la riqueza y solidez de su acervo cultural, Eduardo de la Hera anota: «Además de las ciencias eclesiásticas, conocía las artes plásticas y la poesía, la novela, el teatro, el ensayo, la literatura en general, tanto la clásica como la contemporánea. Poseía, además, una amplia cultura humanística: la de los autores latinos y griegos, que tanto se traducían por entonces en los colegios y seminarios. Alineados en las estanterías de su biblioteca, podían verse, además, libros de filosofía y de historia» (Hera, 184).

${ }^{8}$ Ello lo testimoniará el propio Pablo VI: «[...] Francia, de la que somos personalmente deudores, desde Nuestros primeros años, por tantos elementos preciosos 
«junto al tomismo, considerado en profundidad respecto al planteamiento genérico, encontramos en sus lecturas a los nuevos teólogos, como los alemanes Karl Adam y Romano Guardini; después el dominico P. Cordovani y Newman, Chesterton, Pascal, Gilson, Garrigou-Lagrange, Sertillanges, con predilección por los pensadores que se plantearon el problema de la revitalización del cristianismo en el mundo moderno. No faltan en su biblioteca los grandes de la literatura, como Dostoievski, Tolstoi, Bernanos e incluso Baudelaire [...]»9 .

Es conocida, por otra parte, la recomendación que Mons. Giacinto Gaggia (1847-1933), obispo de Brescia, le hiciera al recién ordenado sacerdote Montini y que él, ya de cardenal, recordará: «"Lee la historia de los Concilios, toma el Hefele (¡18 poderosos volúmenes!) y estúdialos: allí puedes encontrar todo”, me dijo, es decir teología, filosofía, espiritualidad, política, humanismo y cristianismo, errores, discusiones, verdades, abusos, leyes, virtudes y santidad de la Iglesia. La historia de los Concilios es una enciclopedia eclesiástica ${ }^{10}$.

La suya no era, por lo demás, una formación que se circunscribiera a los libros. Ciertamente poseía una nutrida biblioteca — a la que alimentaba con constancia y en la que muchos ejemplares evidencian su atenta lectura con anotaciones y subrayados ${ }^{11}$ _, pero G. B. Montini cultivó asimismo su espíritu con algunos viajes culturales y en el contacto y amistad con grandes pensadores de su tiempo ${ }^{12}$, contacto y amistad que

de Nuestra propia formación» (Discurso al Presidente de Francia, 31/5/1967). «Su preparación teológica, litúrgica, humanística, histórica, literaria debe más a los autores francófonos que a los anglosajones» (L. Crivelli, Montini Arcivescovo a Milano [Milano: San Paolo, 2002], 27). Cf., además, J. Prévotat, "Les sources françaises dans la formation intellectuelle de G. B. Montini", en Paul VI et la modernité dans l'Église (Roma: École Française de Rome, 1984), 101-127.

9 Adornato, 27.

10 G. B. Montini, "I Concilî nella vita della Chiesa”, 25/3/1962, en DsC, 231; DSM III 4996.

11 Cuando se muda de Roma a Milán, por ejemplo, lleva consigo «no menos de 90 cajas de libros —desde Dante a Thomas Mann, desde Agustín a Karl Rahner—» (L. A. Dorn, Pablo VI. El reformador solitario [Barcelona: Herder, 1990], 168). Y Jean Guitton refiere que «en el Vaticano, esa biblioteca personal se ha ampliado y enriquecido: ocupa un piso bajo su apartamento privado» (J. Guitton, Diálogos con Pablo VI [Madrid: Ediciones Cristiandad, 1967], 183-184). Gran parte de sus libros —unos 10.000 volúmenes- se conservan actualmente en el Istituto Paolo VI de Brescia.

12 «Amaba ciertamente los libros, pero más aún a los autores. Era muy feliz de encontrarse con las personas, sobre todo con las personas de fe y de cultura, en un 
siguió alimentando incluso desde la sede pontificia. Muchos de sus contemporáneos, por otra parte, atestiguan cómo el Santo Padre mantenía un vivo interés por el estudio y seguía atentamente el desarrollo de diversas disciplinas ${ }^{13}$. Así lo atestigua, además, el propio Pablo VI:

"Aunque ahora las demasiadas responsabilidades de Nuestro oficio apostólico no Nos permiten tanto tiempo como quisiéramos para lecturas libres y extendidas, no por ello hemos perdido Nuestro antiguo afecto por los libros; por el contrario, estimulado por los mismos deberes de Nuestro ministerio, se encuentra en Nuestro espíritu todavía ávido y operante, como pasión a la que los años no aportan remedio, sino más bien siempre nueva vivacidad» ${ }^{14}$.

En cuanto a la filosofía, sin duda el pensamiento de la escolástica en general y las obras de santo Tomás de Aquino en particular tuvieron un papel fundamental en su formación ${ }^{15}$, como por lo demás era común en

diálogo auténtico, profundo y apasionado. Basta recordar a Jean Guitton, Jacques Maritain, el P. Henri de Lubac, el P. Jean Daniélou, el P. Louis Bouyer, el P. Yves-Marie Congar, el P. Louis Joseph Lebret, los reverendos Charles Journet y Maurice Zundel» (P. Poupard, "Paolo VI: la sua cultura, la sua fede", Notiziario dell'Istituto Paolo VI 23 [1992]: 18).

13 «Pablo VI lee mucho. [...] Sobre su mesa tiene siempre los últimos libros de actualidad y a sus manos llegan directamente periódicos, semanarios y revistas en las más diversas lenguas» (C. Calderón, "Semblanza de Pablo VI", 108). «Siempre se ha reservado, en los intersticios de sus días y de sus noches, momentos de soledad para leer» (Guitton, Diálogos con Pablo VI, 183). «Pablo VI tenía una capacidad notable de lectura y le gustaba consultar muchos libros, también aquellos que contradecían sus ideas» (P. Macchi, "Discussion", 26/10/1980, en Istituto Paolo VI, "Ecclesiam Suam», première lettre encyclique de Paul VI [Brescia: Studium, 1982], 193).

14 San Pablo VI, Discurso a la benemérita familia de "Studium», 10/2/1964.

15 Cf. G. B. Montini, "La festa di S. Tommaso", 8/3/1931, en SF, 471-472; P. Viotto, ed., "S. Tommaso e l'anima giovanile studentesca", Notiziario dell'Istituto Paolo VI 44 (2002): 7-25, donde se presenta y analiza el esquema de una conferencia titulada "La Scolastica di San Tomasso e l'anima giovanile" que pronunciara el P. Montini el 15/3/1928; V. Possenti, "Presenza di Tomasso d'Aquino in Giovanni Battista Montini”, Studium 95 (1999): 365-378. Cf. también la carta apostólica Lumen Ecclesiae, del 5/12/1974, al conmemorarse el VII centenario de la muerte de Santo Tomás de Aquino, en la que San Pablo VI, entre otras cosas, testimonia «el fruto que se obtiene estudiando y consultando sus obras — como sabemos por propia experiencia- y la comprobación del poder persuasivo y formativo que ejerce en sus discípulos, sobre todo en los jóvenes, como pudimos observar en los años de nuestro apostolado entre los universitarios católicos». De él G. B. Montini también dirá: «Para mi cultura preferiré la patrística y la teología en sus autores más cualificados: San Agustín y Santo 
sus años de seminario y de estudios universitarios ${ }^{16}$. A ello se unieron los pensadores del neotomismo — como, por ejemplo, Étienne Gilson, Antonin Dalmace Sertillanges, Réginald Garrigou-Lagrange, Paul Vignaux, Désiré Joseph Mercier, Maurice de Wulf-. Mención aparte merece el francés Jacques Maritain, cuyo pensamiento y obras tanto influyeron en Montini, con quien lo unió además una estrecha amistad ${ }^{17}$.

Su horizonte filosófico no se redujo, sin embargo, al tomismo, sino que, bien afianzado en el conocimiento de la historia de la filosofía y la metafísica, estuvo abierto también a las principales corrientes de su tiempo, asumiendo con espíritu crítico sus aportes y buscando en todo momento iluminarlas con la luz de la $\mathrm{fe}^{18}$. Nos referimos, entre otras, a la fenomenología, el existencialismo, el personalismo y la «filosofía del diálogo», escuelas todas que, con mayor o menor presencia, formaban parte del ambiente intelectual en el que se educó el futuro san Pablo VI. En este rápido repaso de su acervo filosófico debe citarse asimismo a

Tomás, porque son los padres del pensamiento de la Iglesia» (G. B. Montini, "El deseo de santidad", 1945, en $A C D, 61)$.

16 Refiriéndose a los libros filosóficos utilizados por G. B. Montini en sus tiempos de seminarista y de estudiante universitario, conservados en la biblioteca de $\mathrm{Pa}$ blo VI, varios de ellos con anotaciones, Maurilio Guasco señala que «los textos son aquellos en uso en muchos seminarios de su tiempo: los volúmenes de filosofía de Mercier, la Philosophia moralis de Cathrein, en la edición de 1915, y las Disputationes philosophiae moralis, en dos volúmenes, de S. Schiffini, edición de 1891 » (M. Guasco, "La formazione sacerdotale di Giovanni Battista Montini", en Istituto Paolo VI, El sacerdocio en la obra y el pensamiento de Pablo VI [Brescia: Edizioni Studium, 1994], 130).

17 Cf. G. Campanini, "Montini e Maritain”, Studium 80 (1984): 349-358; Ph. Chenaux, Paul VI et Maritain. Les rapports du "montinianisme" et du "maritanisme" (Brescia: Istituto Paolo VI - Edizioni Studium, 1984); Istituto Paolo VI, Montini, Journet, Maritain: une famille d'esprit (Brescia: Edizioni Studium, 1989); R. Mougel, "Maritain, Paul VI et l'Église du Concile”, Notiziario dell'Istituto Paolo VI 39 (2000): 82-100. Pablo VI consideraba que él era "para todos un filósofo de gran valor, un cristiano de fe ejemplar y para Nosotros mismos un amigo particularmente querido» (Telegrama al Prior de los Pequeños Hermanos de Jesús, 29/4/1973), así como «realmente un gran pensador de nuestros días, maestro en el arte de pensar, de vivir y de rezar» (Meditación a la hora del Angelus, 29/4/1973). Téngase en cuenta, además, que el joven Montini había traducido al italiano una de sus obras: Tres reformadores.

18 Son reveladoras estas palabras de Pablo VI que recoge Jean Guitton: «En Roma, sabemos por experiencia muy larga que el tomismo preserva mejor que ninguna otra filosofía, aun escolástica, cierto número de verdades que son necesarias para un buen ejercicio de la fe católica [...], pero no sacamos la consecuencia de que todos los filósofos cristianos deban ser tomistas» (Guitton, Diálogos con Pablo VI, 40-41). 
autores como Blaise Pascal y Henri Bergson, por quienes G. B. Montini cultivó un interés especial.

En lo que respecta a sus estudios teológicos, recibió también una formación clásica, de corte escolástico ${ }^{19}$. Sin embargo, como muchos de su generación, se benefició al mismo tiempo de los aires de renovación que por aquellos años se vivía en Europa. Así pues, la profundización histórica, la vuelta a las fuentes, la lectura de la Sagrada Escritura, el recurso a los Padres de la Iglesia y la consideración de la liturgia como lugar teológico vivificaron sus conocimientos de dogmática.

Por ello, los tratados clásicos de teología -incluidas, naturalmente, las obras de san Agustín, a las que les tenía un particular aprecio ${ }^{20}$-, se complementaron con la lectura de los grandes teólogos de aquel entonces, entre los que se encontraban, por cierto, algunos representantes de lo que con desdén se calificaba como nouvelle théologie. Así pues, los escritos de John Henry Newman, Vito Fornari, Karl Adam, Romano Guardini, Joseph Andreas Jungmann, S. J., Léonce de Grandmaison, S. J., Louis Bouyer, Dom Columba Marmion, Emanuele Caronti, Charles Journet, Henri de Lubac, S. J., Yves Congar, O. P., Jean Daniélou, S. J., entre muchos otros, fueron configurando su vasta cultura teológica.

Por último, es oportuno señalar que dentro del amplio marco de la teología G. B. Montini tuvo una sensibilidad particular hacia algunas disciplinas: en primer lugar, la liturgia - alentado sin duda por los padres oratorianos y por su continuo contacto con los benedictinos ${ }^{21}$-; en

${ }^{19}$ Refiriéndose esta vez a los libros de teología, Guasco señala también que «los textos son aquellos en uso en muchos seminarios de su tiempo: [...] las varias Synopsis theologiae de Tanquerey, en las ediciones de 1913-14 y los cuatro volúmenes de las Institutiones theologiae moralis de Bucceroni, ediciones de 1914-15. No falta, según la praxis de todo buen seminarista, el Summarium theologiae moralis de Arregui...» (Guasco, 130).

20 Cf. G. B. Montini, "L'eredità di Agostino", 1930, en SF, 427-435; "Onoriamo Sant'Agostino", 24/4/1960, en DsMS, 177-186; DSM I 3543-3552. Se conservan las obras completas del Santo de Hipona que pertenecieron a Pablo VI y en cuya primera página del tomo I él mismo escribió: «Estos volúmenes, para mí tan queridos y preciosos...». Elaboró asimismo cinco cuadernillos autógrafos en los que compiló innumerables citas de la obra agustiniana, ordenadas temáticamente en un índice (cf. G. Díaz y S. Miscioscia, Pablo VI cita a San Agustín. Apuntes del Papa Montini [1954-1978] [Madrid: Ediciones Escurialenses, 2004]). Cf., además, sus palabras de 1945 recogidas supra, nota 15.

21 Cf. G. B. Montini, "Dogma e liturgia”, 1928, en SF, 232-235; M. Trebeschi, "Il pensiero teologico del giovane Montini: la liturgia", Brixia sacra 1-2-3-4 (1986): 
segundo término, el derecho canónico —al que dedicó estudios especializados propios de su labor en la Secretaría de Estado ${ }^{22}$-; y, finalmente, la cristología - lo que le daría a toda su teología una impronta marcadamente cristocéntrica ${ }^{23}$ - Mención aparte merece, por su importancia en sí misma y por el tema del presente artículo, la eclesiología, a la que consagraremos el siguiente apartado.

\section{ECLESIOLOGÍA}

\subsection{FORMACIÓN}

Como el propio G. B. Montini confesó siendo arzobispo de Milán, ya de «jovensísimo sacerdote [...] pensé dirigir [mis estudios] precisamente a la vida y a la historia de la Iglesia» ${ }^{24}$. Si bien, como sabemos, no pudo concretar expresamente este deseo porque el Señor tenía preparados para él otros caminos, "para nadie es un secreto con cuánto amor y particular atención ha cultivado, desde que era joven sacerdote, la doctrina teológica referida a la Iglesia, siguiendo después, también de Cardenal y de Papa, los desarrollos de la misma a través de las obras de los mejores autores $»^{25}$. Él, por su parte, fue aprovechando las diferentes vivencias que su ministerio le ofrecía para seguir ahondando en el estu-

107-130; V. Pontiggia, "Le fonti giovanili del pensiero di Paolo VI sulla liturgia”, Notitiae 24 (1988): 543-565; C. Manziana, "La formation liturgique de G. B. Montini", en Istituto Paolo VI, Le rôle de G. B. Montini-Paul VI dans la réforme liturgique (Brescia: Edizioni Studium, 1987), 23-31.

22 Así lo testimonia en la conferencia de 1951 ya referida: «No se habló más de estudios literarios; y mi itinerario se inclinó hacia los estudios jurídicos y diplomáticos» (G. B. Montini, "Discorso in occasione del $250^{\circ}$ anniversario della Pontificia Accademia Ecclesiastica", p. XV). Cf. también G. B. Montini, La "Responsio super Nunciaturis" di Papa Pio VI. Appunti delle lezioni del Sac. G. B. Montini per il corso di "Storia della Diplomazia Pontificia" (Roma: Edizioni Studium, 1937) y supra, nota 5.

${ }_{23}$ Cf. G. B. Montini, Introduzione allo studio di Cristo. Schemi di lezioni per studenti di scuole superiori (Roma: Editrice Studium, 1934); V. Levi, ed., Il Gesù di Paolo VI (Milano: Mondadori, 1985); F. Molinari, "Il Gesù del giovane Montini", Studium 77 (1981): 675-688.

${ }^{24}$ G. B. Montini, "I Concilî nella vita della Chiesa", 25/3/1962, en DsC, 231; DSM III 4996.

25 G. Caprile, "Aspetti positivi della terza sessione del Concilio", La Civiltà Cattolica 116/I (1965): 336-337. 
dio y la comprensión del Cuerpo Místico de Cristo ${ }^{26}$. En ese sentido, su estancia en la Santa Sede le sirvió también como un observatorio excepcional para presenciar «el fermento fecundo del pensamiento filosófico y teológico de aquellos años - determinantes sobre todo para la eclesiología—», lo que constituyó para el

«Pro-Sustituto de la Secretaría de Estado una ocasión única y privilegiada para acceder directamente, poco después de su publicación y en ciertos casos incluso antes, a las ideas discutidas y, más de una vez, inclusive a las personas que las sostenían y las contrastaban, para obtener, gracias a la libre integridad de su conciencia y al infalible sensus Ecclesiae madurado por años en la oración y en la experiencia meditada de vida, toda la fuerza impetuosa de la renovación histórica en curso, en el momento mismo en que se producía» ${ }^{27}$.

Y este interés, que fue encontrando a cada paso nuevas maneras de expresarse, continuó acompañándolo durante todo su ministerio petrino ${ }^{28}$.

Son muchos los autores que tuvieron algún papel significativo en la formación eclesiológica de G. B. Montini, desde historiadores de la Iglesia —el ya mencionado Karl Joseph von Hefele, Joseph Hergenröther, Hubert Jedin, Ludwig von Pastor, Pierre Batiffol, Henri Daniel-Rops, Roger Aubert, Louis Duchesne-, pasando por algunos pensadores de los siglos anteriores - Jacques Bénigne Bossuet, Johann Adam Möhler, Matthias Joseph Scheeben, John Henry Newman-y continuando con otros relativamente contemporáneos a él —Romano Guardini, Jean Jérôme Hamer, O. P., Herbert Dieckmann, Giuseppe Siri, Louis Billot, S. J.,

${ }^{26}$ Así, por ejemplo, entiende él mismo su largo servicio en la Secretaría de Estado: «Roma, donde hemos pasado la mayor parte de nuestra vida, siempre esforzándonos por penetrar en el misterio de la Iglesia, mientras con un humilde pero asiduo esfuerzo prestábamos nuestro trabajo a las oficinas de la Sede Apostólica» (G. B. Montini, Carta pastoral Pensiamo al Concilio, 22/2/1962, n. 3, en DsC, 157).

27 V. Peri, “Appunti per un'indagine sull'ecclesiologia di Paolo VI. Titoli di originalità dell' «Ecclesiam Suam»", Rivista di Storia e Letteratura Religiosa 17 (1981): 441.

28 Evidenciando cómo la Iglesia fue tema constante en el magisterio montiniano, Davide Marzaroli anota: «Comentar y precisar la eclesiología conciliar, con espíritu profundamente exegético, ha sido uno de los empeños constantes del pontificado de Pablo VI. Es raro, de hecho, encontrar un documento, una alocución, una catequesis, una intervención del Papa Montini en que no se encuentre al menos una referencia a la eclesiología» (D. Marzaroli, "Pablo VI, artífice y exegeta de la eclesiología postconciliar", Ecclesia. Revista de cultura católica 2 [1997]: 195). 
Hubert Clérissac, O. P., Roger Hasserveldt, Adolphe Tanquerey, Lucien Cerfaux, Wilhelm Bertrams, Ambroise de Poulpiquet, O. P.-. Como se puede ver en este breve e incompleto elenco, se trata de pensadores de diversos tiempos y escuelas teológicas, con propuestas y acentos también distintos. Cuatro, sin embargo, parecen ser los que más influyeron en su concepción de la Iglesia.

En primer lugar, Charles Journet (1891-1975), el célebre autor del monumental tratado sobre La Iglesia del Verbo Encarnado (3 tomos: 1941, 1951, 1969). Se trata de uno de los teólogos más citados en los escritos eclesiológicos montinianos, no solo cuando era arzobispo de Milán, sino también como pontífice. Antiguo amigo del Santo Padre ${ }^{29}$, este famoso seguidor de la doctrina de santo Tomás, en reconocimiento por su aporte al estudio de la Iglesia antes y durante el Concilio, fue creado cardenal por el propio Pablo VI en el primer consistorio de su pontificado. La de Journet es una «influencia real, profunda», "una presencia vibrante y efectiva que estructura el pensamiento y la enseñanza» ${ }^{30}$ de $\mathrm{G}$. B. de Montini. Aunque, entre otros aportes, podrían destacarse el acento cristológico, el énfasis en la relación de la Iglesia con el Espíritu Santo y sus reflexiones sobre las notas de la comunidad eclesial, «no es sólo sobre uno u otro punto en particular que Pablo VI hace referencia a Journet, sino más bien a toda su síntesis» ${ }^{31}$.

29 De él dirá Pablo VI: «El Cardenal Charles Journet, que desde hace tantos años es para nosotros un maestro y un amigo...» (Discurso a los miembros del Episcopado Suizo, 10/6/1969). Y en otro momento elogiará a «este hombre de Iglesia que tanto ha contribuido al progreso de la fe por la profundidad y la seguridad de su pensamiento en sus obras escritas y en sus enseñanzas y por el testimonio de su vida ejemplar» (Telegrama al Presidente de la Conferencia Episcopal Suiza, 16/4/1975).

30 J.-P. Torrel, O. P., "Paul VI et le Cardinal Journet. Aux sources d'une ecclésiologie”, Notiziario dell'Istituto Paolo VI 13 (1986): 65.

31 Ibid., 66. El P. Congar, de quien hablaremos a continuación, por su parte señala: «Yo pienso que Pablo VI venía de la época de Pío XII y su referencia eclesiológica es principalmente Journet» (Y. Congar, "Situation ecclésiologique au moment de «Ecclesiam Suam»", en Istituto Paolo VI, "Ecclesiam Suam», première lettre encyclique de Paul VI, 114). Y el P. Pasquale Macchi, secretario particular de Pablo VI, testimonia: «Estoy seguro de que [el Santo Padre] consultó muchísimas veces los volúmenes sobre la Iglesia de Charles Journet» (Macchi, 187). Cf., además, G. Boissard, "La relation Montini-Journet", y Ch. Morerod, "Montini et l'ecclésiologie de Journet", ambos en Istituto Paolo VI, Montini, Journet, Maritain: une famille d'esprit, 10-47 y 140-171, respectivamente. 
En segundo término, el dominico Yves Congar (1904-1995), reconocido como uno de los teólogos más importantes e innovadores del siglo $\mathrm{XX}$, y cuyas obras Cristianos desunidos. Principios de un "ecumenismo" católico (1937), Ensayos sobre el misterio de la Iglesia (1941), Verdadera y falsa reforma en la Iglesia (1950) y Jalones para una teología del laicado (1953), entre otras, son citadas por Montini incluso más que las de Journet, igualmente antes y después de asumir la Cátedra de Pedro. El acento que le otorgaba a la historia en el estudio de la teología, su labor pionera en los campos del ecumenismo y del laicado, así como su empeño por buscar una síntesis de las dimensiones cristológica y pneumatológica de la Iglesia, remarcando los aspectos invisibles de la misma, son algunas de las notas más saltantes de la eclesiología de Congar que parecen haber enriquecido el pensamiento montiniano ${ }^{33}$.

A ellos se une el también francés Henri de Lubac, S. J. (1896-1991), a cuya pluma se deben obras tan significativas como Catolicismo. Aspectos sociales del dogma $(1938)^{34}$, El drama del humanismo ateo $(1944)^{35}$, Corpus Mysticum (1944), El misterio de lo sobrenatural (1946), y su trascendental Meditación sobre la Iglesia (1953), esta última leída por mons. Montini apenas aparecida en su original francés ${ }^{36}$. Con su valoración

${ }^{32}$ El propio P. Congar cuenta que «el Cardenal Montini me escribió un día para pedirme un ejemplar de Verdadera y falsa reforma» (Congar, 179).

${ }_{33}$ Cipriano Calderón manifiesta que «Congar ha sido siempre uno de sus teólogos preferidos» (C. Calderón, "El estudio de los temas eclesiales apasionó a Pablo VI desde su juventud", Hechos y dichos, 42 [1965]: 652-655). Eduardo de la Hera confirma a su vez que el eclesiólogo francés era «uno de los teólogos más importantes del Vaticano II y hombre de confianza de Pablo VI» (Hera, 646).

${ }^{34}$ Este no solo fue el primer libro de De Lubac traducido al italiano, sino que esa edición (Roma 1948) estuvo a cargo de la editorial Studium, tan cercana a G. B. Montini.

35 Cuenta el propio cardenal De Lubac que, a poco de ser nombrado arzobispo de Milán, mons. Montini dio «una conferencia, a la que habían sido invitados el alto clero, los embajadores y otros personajes; trató sobre la Iglesia ante el ateísmo contemporáneo y explicó a continuación que lo esencial de su exposición estuvo tomado del Drame de l'humanisme athée, obra cuya lectura recomendaba a sus oyentes» (H. de Lubac, Memoria en torno a mis escritos [Madrid: Ediciones Encuentro, 2000], 164).

36 Nuevamente es el mismo De Lubac quien narra que en 1955 «la edición italiana aparecía en Milán, bajo la protección del nuevo arzobispo, Mons. Montini, quien más de una vez tuvo a bien citar la obra y distribuirla entre su clero» (Lubac, 164). Uno de los sacerdotes de la arquidiócesis de Milán mientras G. B. Montini era su pastor, el P. Eugenio Fornasari, quien además estaba vinculado a una librería que proveía de libros al cardenal, testimonia: «Recuerdo que le agradó sobremanera el 
tan grande de la Tradición, su constante recurso a las fuentes, sus abundantes referencias patrísticas, su preocupación por destacar los nexos que unen a la Iglesia con la Eucaristía y su aproximación simbólica a la Iglesia este erudito pensador "le sirvió de frecuente meditación» ${ }^{37}$ a Pablo VI. Su confirmación como perito en el Concilio Vaticano II y su nombramiento como miembro de la recientemente creada Comisión Teológica Internacional —entre 1969 y 1974 - no fueron sino una pequeña muestra de la admiración intelectual que el papa Montini tenía hacia él ${ }^{38}$.

Finalmente, el italiano Carlo Colombo (1909-1991), amigo personal del Santo Padre y uno de los peritos más consultados por el entonces arzobispo de Milán en el primer periodo del concilio, consultas que continuaron incluso - ya elegido para la Cátedra de Pedro- durante las

libro del padre Henri de Lubac Meditación sobre la Iglesia. Un íntimo colaborador suyo me dijo que después del cónclave en que había salido elegido Papa encontraron en el arzobispado ese libro sobre la mesa de su escritorio. Estaba lleno de observaciones y anotaciones marginales, hechas de puño y letra por el cardenal» (E. Fornasari, "Mi Cardenal", 1963, en J. L. González, Encuentros con Pablo VI [Bilbao: Paulinas, 1968], 79). Y el P. Giacomo Martina, S. J., señala que «este último libro [Meditación sobre la Iglesia ], en el que se funde una gran erudición con un sólido conocimiento de la patrística y un profundo sensus ecclesiae, fue apasionadamente leído una y otra vez por mons. Montini, especialmente la brillante descripción del an $\mathrm{r}$ eccl siasticos» (G. Martina, "El contexto histórico en el que nació la idea de un nuevo Concilio ecuménico", en R. Latourelle, ed., Vaticano II: balance y perspectivas [Salamanca: Ediciones Sígueme, $\left.\left.1990^{2}\right], 50\right)$.

37 Así lo cuenta el ya mencionado P. Macchi, 187. Según testimonia Jean Guitton, el propio Pablo VI comentaba: «El p. De Lubac brindará excelentes servicios a la Iglesia. Conocemos su ciencia, sus méritos, su influencia. [...] El retorno, propuesto por el p. De Lubac, a la tradición de los Padres, sobre todo a los Padres griegos, es algo perfecto" (J. Guitton, Paolo VI segreto [Milano: San Paolo, 1985], 45; cf. también ibid., 58, 104 y 127).

${ }_{38}$ Poco antes de ser elegido pontífice, el 18/4/1962, el card. Montini le escribió una breve carta en la que le compartía: "Siempre leo con mucho interés, y espero también con provecho, sus libros, si bien las obligaciones de mi ministerio no me conceden mucho tiempo para la lectura y muy poco para el estudio» (cit. en Lubac, 237; cf., además, ibid., 164-165, 175-177 y 432). Sorprenden asimismo los elogiosos términos con que años después, en su octogésimo cumpleaños, Pablo VI se dirige al reconocido sacerdote "de la Compañía de Jesús, para la que eres una gloria», y le envía «esta carta Nuestra para, a la vez que te manifestamos nuestro gozo de padre, hagamos pública, al mismo tiempo, la egregia estima en que te tenemos, así como podamos expresarte el agradecimiento en nombre tanto Nuestro como de la Iglesia» (“Pablo VI al R. P. Henri de Lubac, S. J.”, Stromata 33 [1977]: 127). 
restantes sesiones del Vaticano II. Más allá de ser un estudioso menos renombrado que los anteriores y de las esporádicas citas que G. B. Montini realiza de un ensayo suyo sobre Episcopado y primado pontificio en la vida de la Iglesia (1960), fueron continuos sus consejos teológicos y eclesiológicos ${ }^{39}$.

No se puede olvidar, por otra parte, aunque por cierto a un nivel distinto, el influjo que sin duda tuvo en él la encíclica Mystici Corporis (1943) de Su Santidad Pío XII. Cercano colaborador hasta 1939 del entonces cardenal Eugenio Pacelli y luego, como sustituto de la Secretaría de Estado, del propio Pío XII en tiempos en que se redactó la encíclica, este documento dejó indudablemente honda huella en mons. Montini, como lo testimonian, además, las constantes referencias que hace de este importante documento pontificio ${ }^{40}$.

39 Mons. Colombo, por largo tiempo profesor de teología en la Facultad teológica milanesa, de la que llegó a ser su rector, fue nombrado por Pablo VI obispo auxiliar de Milán el 7 de marzo de 1964, con lo cual pudo participar como padre conciliar en la tercera y cuarta sesión del Vaticano II. El P. Giacomo Martina destaca que «el cardenal Montini lo consultó frecuentemente, por lo que se hablaba de mons. Colombo como del teólogo de Montini»(G. Martina, "Paolo VI e la ripresa del Concilio", en Istituto Paolo VI, Paolo VI e i problemi ecclesiologici al Concilio [Brescia: Edizioni Studium, 1989], 50, nota 69). Franco Giulio Brambilla, por su parte, ofrece sugerentes informaciones sobre los vínculos intelectuales que unieron a este «teólogo discreto y reservado de Pablo VI, y al entonces Cardenal de Milán» en relación al Vaticano II; cf. F. G. Brambilla, "Carlo Colombo e G. B. Montini alle sorgenti del Concilio", La Scuola Cattolica 130 (2002): 221-260; "La ricerca faticosa di una via per il Concilio: Giovanni XXIII e Montini-Paolo VI”, Teologia 37 (2012): 335-360, especialmente 336346 y 351-355.

40 Resulta revelador conocer lo que el entonces arzobispo Montini opinaba sobre este documento de su predecesor: "Tenemos la gran carta sobre el Cuerpo místico que es la Iglesia, "Corporis mystici quod est Ecclesia": la doctrina sobre la Iglesia encuentra en ella un tratamiento sintético y muy autorizado, y abre tanto a los estudios teológicos como a las corrientes espirituales un amplio y muy fecundo campo» (G. B. Montini, "L'aspetto religioso del pontificato di Pio XII", 27/2/1956, Notiziario dell'Istituto Paolo VI 17 [1988]: 30). Y en otro momento apuntaba: «La encíclica sobre el Cuerpo Místico (Mystici Corporis, 1943) nos habla admirablemente de la Iglesia, no ya bajo el aspecto jurídico y exterior, sino bajo el teológico y mistérico, proporcionando al estudio y a la piedad una bella síntesis de las verdades que nos enseñan cómo en la Iglesia vive Cristo, y en ella y con ella continúa en el tiempo su presencia y su obra» (G. B. Montini, "Considerazioni sul Magistero di S. S. Pio XII”, 1956, Notiziario dell'Istituto Paolo VI 17 [1988]: 36). Nótese la afinidad de estas ideas con lo que más adelante señalamos sobre los principales rasgos de la eclesiología montiniana (cf. infra, 3.3). Por ello, en opinión de G. Colombo, «no se yerra si se afirma que, en lo 


\subsection{EsCRITOS ECLESIOLÓGICOS}

Todo esto se fue plasmando a lo largo de los años en diferentes escritos dedicados a profundizar en algún aspecto del misterio de la Iglesia. No se trata, sin embargo, de estudios sistemáticos o desarrollos completos - sus responsabilidades laborales y ministeriales no se lo permitieron-, sino más bien de trabajos parciales y circunstanciales, respondiendo a alguna invitación concreta o a una necesidad pastoral específica. Especialmente a partir de 1959 se da, como es lógico suponer, una orientación en la temática hacia el, entonces recientemente convocado, Concilio Vaticano II.

Entre sus principales escritos eclesiológicos se encuentran, en primer lugar, un trabajo poco conocido, elaborado en los primeros años de su ministerio sacerdotal, cuando era asistente de la Federación Universitaria Católica Italiana (FUCI), que se titula precisamente La Chiesa [ La Iglesia], y que fue preparado como parte de un programa de formación para los jóvenes universitarios por los años 1926-192741.

Años más tarde, ya como arzobispo de Milán, podemos mencionar, entre muchos otros, el radiomensaje que pronunció en 1957 con ocasión de la Gran Misión Arquidiocesana sobre La Iglesia en sus aspectos esenciales. Teniendo en mente sobre todo a los alejados, procura mostrar con lenguaje sencillo «el rostro de la Iglesia», a la que entiende como «la continuación de Cristo y el punto de encuentro, móvil en la historia, entre Dios y los hombres», el "camino al Padre» y el ámbito comunitario en el que vencemos el individualismo. Luego de señalar que «la Iglesia tiene dos rostros, uno externo, que puede aparecer desgastado y manchado por el tiempo y la tierra; el otro interno, que es todo santo y santificante», se detiene concisamente a ilustrar su aspecto histórico — prefigurada en el Antiguo Testamento, «la venida de Cristo en el seno del pueblo

que respecta a la naturaleza íntima de la Iglesia, la eclesiología del Papa Montini es la de la Mystici Corporis» (G. Colombo, "Genesi, storia e significato dell'enciclica «Ecclesiam Suam»", en Istituto Paolo VI, "Ecclesiam Suam», première lettre encyclique de Paul VI, 142). Se pueden ver otras referencias montinianas a la Mystici Corporis en DsC, 19, 82, 83, 89, 97, 120, 121, 164, 225.

41 Fue apareciendo publicado, durante esos años, en la revista Studium 22 (1926): 583-587 y 23 (1927): 44-47, 103-105 y 162-170. Pero al no haber sido firmado, este texto presenta problemas de autoría. G. B. Montini, sin embargo, «en los cursos sucesivos, remite varias veces a él» (M. Trebeschi, "Il pensiero teologico del giovane Montini: la liturgia”, Brixia sacra 1-2-3-4 [1986]: 112, nota 19). 
elegido ha ampliado sus confines a todos los que con la Fe y la Gracia se adhieren a Él»—, místico — «la Iglesia no es solamente una sociedad visible con fines religiosos, sino un misterio»—y jerárquico — pues «la Iglesia no está formada por elementos homogéneos (como un mineral), sino por elementos diferentes, como todo organismo viviente»- Finalmente, concluye con una breve explicación de la parroquia, "pequeña porción de la Iglesia» en la que «todos tienen algo que hacer y no solamente que recibir» ${ }^{42}$.

La conferencia en el II Congreso Mundial para el Apostolado de los Laicos, que se celebró en Roma en octubre de 1957 y que tuvo por título La misión de la Iglesia. Esta, explicaba entonces, "consiste en prolongar en el mundo la vida de Cristo, y hacer participar a la humanidad en Sus misterios: la Encarnación y la Redención». No es, por ello, una tarea meramente humana, sino que tiene su origen en Cristo y, para ser auténtica, debe contar con dos características: «la ortodoxia y el mandato». Saliendo a continuación al paso de algunas malinterpretaciones o reduccionismos temporales, precisa también que «la misión cristiana es esencialmente religiosa. No es directamente ni política, ni social, ni económica. Se refiere al hombre en lo que respecta a su fin supremo». Perfilando luego "el campo del apostolado», dirá que la Iglesia está llamada a cumplir con su misión de ser Madre y Maestra, de presentar a Cristo como prototipo de humanidad plena y de dispensar la vida sacramental «en el mundo contemporáneo», un mundo que hay que amar, pero frente al cual hay que mantener también una actitud de constante vigilancia. Dado el motivo del congreso, el cardenal Montini se detiene de manera especial en «la vocación apostólica de los laicos», quienes tienen un rol especial, pues «en el contacto de la misión de la Iglesia con el mundo ellos son los testigos más próximos, quienes ven y viven los fenómenos». Por ello, los urge tanto a una audaz actividad evangelizadora como a la dependencia y comunión con la jerarquía ${ }^{43}$.

La caridad de la Iglesia hacia los alejados, ponencia en la VIII Semana Nacional de actualización pastoral que se llevó a cabo en Milán en septiembre de 1958, y en la que, como el mismo título indica, aborda el aún hoy actual "problema de los "alejados"». Luego de presentar "las razones por las cuales la Iglesia debe cuidar de ellos», procura explicar «los

${ }^{42}$ G. B. Montini, "La Chiesa nei suoi aspetti essenziali”, 1957, en $D s C$, 3-13.

43 G. B. Montini, "La missione della Chiesa", 9/10/1957, en DsC, 15-41; DSM I 1662-1683. 
caminos del apostolado, esto es, los medios, los métodos, las formas de la presentación del mensaje cristiano» que han de utilizarse en esta delicada misión. Si, por un lado, se requiere de la «sensibilidad pastoral», de la cercanía, «no de crítica sino de amor», por el otro no se ha de olvidar «la firmeza doctrinal de la Iglesia», el hecho de que ella «no puede negar o minimizar la verdad, cuyo depósito inviolable se le ha encargado custodiar y difundir». Es importante asimismo conocer a los alejados, tanto en sus expresiones culturales como en sus particularidades individuales, para poder ofrecerles luego «la presentación genuina de la religión de Cristo y nuestro prudente, diligente, ardiente y paciente acercamiento personal $»^{44}$. Se trata de palabras que anticipan y tienen una gran sintonía con esa actitud pastoral que tanto san Juan XXIII como el Concilio Vaticano II van a proponer como el modo de la Iglesia de acercarse al mundo contemporáneo ${ }^{45}$.

Su intervención en el curso de Estudios Cristianos que se desarrolló en agosto de 1960 en Asís y que estuvo dedicada a tratar sobre Unidad y Papado en la Iglesia. En ella explica no solo el contenido de cada uno de estos dos términos, aclarando asimismo los errores y malinterpretaciones de que han sido objeto, sino que evidencia al mismo tiempo su mutua implicancia: «El Papado es necesario para que la unidad se dé en la Iglesia». Dicho en otros términos, «en el sucesor de Pedro, es decir en el Papado, se realiza aquella "nota" de unidad, o mejor dicho, de unicidad, que distingue y caracteriza a la Iglesia de Cristo. Mediante la apostolicidad alcanzamos la unidad», y esto no por decisión humana o por acuerdo de la comunidad, sino por institución del propio Señor Jesús. La unidad, sin embargo, no debe entenderse como uniformidad, sino como «inserción en una comunión». Tampoco debe ser un dato "puramente histórico y jurídico, esto es referido sólo a los hombres que de ella forman parte, al rostro visible y concreto de la Iglesia, sino que debe ser comprendido también en relación a Cristo y a Dios». El papado, por su

${ }^{44}$ G. B. Montini, "La carità della Chiesa verso i lontani", 1958, en $D s C$, 43-61; DSM II 2319-2334.

45 Más allá de las diferencias de temperamento, estilo y forma de gobierno, entre san Juan XXIII y san Pablo VI hubo una clara línea de continuidad. El extenso epistolario que intercambiaron -más de 200 cartas- es un testimonio más que elocuente de su profunda comunión espiritual; cf. A. G. Roncalli - G. B. Montini, Lettere di fede e amicizia (1925-1963) (Brescia: Istituto Paolo VI - Edizioni Studium, 2013). Cf. también Ph. Chenaux, ed., Giovanni XXIII e Paolo VI. I due Papi del Concilio (Roma: Lateran University Press, 2013). 
parte, al que se le han garantizado el primado, la infalibilidad y la indefectibilidad, no es un poder arbitrario y tiránico, sino «centro representativo y promotor de esta unidad» ${ }^{46}$.

Las palabras que impartió en noviembre de 1960 al inicio de una misión en Florencia sobre Lo que la Iglesia es y no es. Después de analizar algunos de los fenómenos culturales y de las actitudes erradas que llevan a una incomprensión del Cuerpo de Cristo en nuestro tiempo, plantea la necesidad de "volver a entender a la Iglesia», "volverse a dar un concepto reflejo, más preciso, más esencial» de ella. Es justamente lo que pretende a continuación, comenzando con reconocer que «una de las deformaciones más usuales del rostro radiante de la Iglesia lo ofrecen precisamente muchos de los hombres que la componen y que, lamentablemente, a veces la representan», lo que "constituye un dolor continuo y ardiente para quien ama a la Iglesia». Luego explica por qué «no es una institución vetusta y conservadora» que ha quedado relegada en el pasado, tampoco «maestra de una doctrina apriorística, incomprensible, indiscutible e inmóvil» que representa un obstáculo para el avance de la ciencia, y mucho menos «la deformación de Cristo» que ha alterado el genuino mensaje de su Fundador o se ha alejado de Su ejemplo de vida. Ella es, más bien, «un misterio», que requiere de la gracia y de la fe para ser rectamente entendido. Ella es, asimismo, el «Cuerpo Místico» de Cristo que, como la misma expresión lo indica, posee dos aspectos: uno "espiritual y divino» y otro «visible y humano». Ella es, en fin, una «Madre» que nos otorga "la verdadera vida», nos alimenta con «los sacramentos», "nos instruye» y «nos ama». Por ello «llamar "Madre" a la Iglesia significa volverla a entender y amarla ${ }^{47}$.

A ello se añaden una serie de trabajos de diversa índole que tienen al Vaticano II como tema central y que quieren servir a su adecuada preparación. Nos referimos, por ejemplo, al documento con sus opiniones y votos para el buen desempeño del concilio que redactó en mayo de

46 G. B. Montini, “Unità e Papato nella Chiesa”, 29/8/1960, en DsC, 77-99; DSM II 3742-3761.

47 G. B. Montini, “Ciò che la Chiesa è e non è", 10/11/1960, en DsC, 101-127; DSM II 3888-3907. En opinión de Cipriano Calderón, esta conferencia «representa uno de los textos más finos y originales escritos en estos años sobre la realidad de la Iglesia y sobre los aspectos de la misma que más interesan al hombre moderno» (Calderón, “Semblanza de Pablo VI", 96). 
196048; la prolusión Los Concilios Ecuménicos en la vida de la Iglesia en el XXXII curso de actualización cultural, en agosto de $1960^{49}$; la conferencia Los Concilios en la vida de la Iglesia pronunciada en la Universidad Católica del Sagrado Corazón de Milán en marzo de 196250; el discurso en el Instituto para los Estudios de Política Internacional sobre El Concilio Ecuménico en el cuadro histórico internacional, en abril de 1962 $2^{51}$; sus palabras sobre Roma y el Concilio en el Campidoglio, en octubre de 1962, para la inauguración de un ciclo de conferencias sobre los concilios ecuménicos ${ }^{52}$; la carta del 18 de octubre de 1962 al cardenal secretario de Estado presentándole algunas preocupaciones y sugerencias sobre el recién inaugurado concilio $^{53}$; las comunicaciones semanales que fue enviando a la arquidiócesis de Milán, entre octubre y diciembre de 1962, mientras asistía a la primera sesión del Vaticano II $^{54}$; su intervención sobre el esquema De Ecclesia en el aula conciliar el 5 de diciembre de 196255; o sus palabras en Varese sobre Los sacerdotes

${ }^{48}$ Cf. "Pareri e voti per la buona riuscita del Concilio", 8/5/1960, Notiziario dell'Istituto Paolo VI 6 (1983): 41-52; DSM II 3582-3588.

${ }^{49}$ Cf. G. B. Montini, "I Concilî Ecumenici nella vita della Chiesa", 16/8/1960, en DsC, 131-151; DSM II 3719-3738.

50 Cf. G. B. Montini, "I Concilî nella vita della Chiesa”, 25/3/1962, en DsC, 217237; DSM III 4985-5001.

${ }^{51}$ Cf. G. B. Montini, "Il Concilio Ecumenico nel quadro storico internazionale", 27/4/1962, en DsC, 195-215; DSM III 5077-5095.

52 Cf. G. B. Montini, "Roma e il Concilio", 10/10/1962, en $R C$-LC, 5-19; DSM III 5348-5361.

53 Cf. G. B. Montini, "Lettera al Cardinale Amleto Cicognani”, 18/10/1962, Notiziario dell'Istituto Paolo VI 7 (1983): 11-14; DSM III 5366-5370. Como hace notar F. G. Brambilla, «la carta de Montini parece ser una de las cosas más lúcidas y sinceras del primer período [del Vaticano II] y representa la figuración del futuro Papa con respecto al Concilio, incluidas sus exploraciones temporales. Es casi su índice premonitorio" (F. G. Brambilla, "La ricerca faticosa di una via per il Concilio: Giovanni XXIII e Montini-Paolo VI”, Teologia 37 [2012]: 350).

${ }^{54}$ Cf. G. B. Montini, "Lettere dal Concilio", 1962, en $R C-L C, 21-52$; también en DSM: $1^{\text {a }}$, III 5361-5365; $2^{\text {a }}$, III 5370-5375; $3^{\text {a }}$, III 5389-5391; $4^{\text {a }}$, III 5395-5398; $5^{\text {a }}$, III

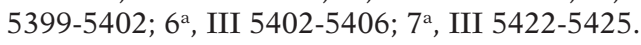

55 Cf. "Intervención en la Congregación General XXXIV sobre el esquema De Ecclesia", 5/12/1962, en Acta Synodalia Sacrosancti Concilii Oecumenici Vatican II, vol. I (Periodus Prima), pars IV (Congregationes Generales XXXI-XXXVI) (Civitas Vaticana: Typis Polyglottis Vaticanis, 1971), 291-294; DSM III 5426-5429. En opinión de Jan Grootaers, «el discurso del 5 de diciembre fue escuchado con la más sostenida atención por el Concilio entero» y «fue percibido y recibido como una de las tomas de posición más importantes de este primer período» (J. Grootaers, "L’attitude de 
y el Concilio Ecuménico en un congreso de estudio para sacerdotes en febrero de $1963^{56}$. Estos y otros escritos, además de evidenciar sus conocimientos eclesiológicos, muestran su gran sentido eclesial y su disponibilidad a leer los signos de los tiempos.

Dentro de este último grupo destaca la carta pastoral Pensemos en el Concilio, escrita para la Cuaresma de 1962. Ya próxima a inaugurarse la asamblea conciliar, el arzobispo Montini quiere invitar a los fieles de su arquidiócesis a considerar "la importancia de este evento» que involucra a todos los miembros del Cuerpo Místico, y para ello les explica las principales nociones de lo que es un concilio ecuménico, su sentido «no sólo histórico y exterior», sino "también interior, espiritual, humano y religioso», los temas que posiblemente abordará y la forma en la que cada uno puede cooperar, además de la oración, para su buen desarrollo. «Es la Iglesia toda la que se expresa en el Concilio, y nosotros somos la Iglesia», señala; sin embargo, es preciso recordar que este acontecimiento histórico «no tiene como protagonistas solamente a hombres de este mundo, sino también, y con mayor título, al Espíritu vivificante, que anima a la Iglesia de Cristo». A lo largo de la carta va hilvanando importantes enseñanzas eclesiológicas, como, por ejemplo, «el misterio divino de la Iglesia» - ella «no es sólo una institución visible y compuesta de hombres», sino "un diseño divino, una presencia divina, una acción divina», en fin, «un misterio que hay que buscar en la mente de Dios»-; «el primado de Pedro» y su relación tanto con el Colegio Episcopal «en cuanto sucesor del Colegio Apostólico» como con el concilio ecuménico; «su misión salvífica universal», que incluye, por cierto, la búsqueda de la unidad con «los hermanos separados»; o el papel de los «buenos y fieles laicos católicos», que como parte de su «ardua y bellísima labor de la consecratio mundi» deben "penetrar de principios cristianos y de

l'archevêque Montini au cours de la première pèriode du Concile (octobre 1962-juin 1963)", en Istituto Paolo VI, Giovanni Battista Montini, Arcivescovo di Milano e il Concilio Ecumenico Vaticano II, 274 y 276). Poniendo de relieve su gran trascendencia en el curso de la asamblea conciliar, el ya referido mons. Brambilla anota asimismo que «el discurso de Montini del 5 de diciembre pareció indicar la ruta del Concilio. [...] Con el Discurso de diciembre el magisterio de Montini alcanza quizás uno de sus momentos más altos» (F. G. Brambilla, "La ricerca faticosa di una via per il Concilio: Giovanni XXIII e Montini-Paolo VI”, Teologia 37 [2012]: 350 y 356).

56 Cf. G. B. Montini, "I sacerdoti e il Concilio ecumenico", 6/2/1963, en DsCon, 202-213; DSM III 5567-5578. Cf., además, id., Un'ora nuova nella storia. Discorsi e scritti dell'arcivescovo sul Concilio (Milano: Centro Ambrosiano, 2012). 
fuertes virtudes naturales y sobrenaturales la inmensa esfera del mundo profano». Es interesante notar cómo en varios párrafos se percibe una gran consonancia con lo que poco después expondrá la Constitución $\mathrm{Lu}$ men gentium, como lo ya mencionado sobre el primado y el Colegio Epis$\operatorname{copal}^{57}$, o su explicación de la relación de la Iglesia con las personas de la Trinidad - tiene su origen «en Dios que busca a su pueblo», «es la continuación de Cristo en el tiempo y la dilatación de Cristo sobre la tierra», y «el Espíritu Santo es enviado por Jesús como el animador de la Iglesia, y crea en ella la gracia, con sus carismas y sus dones» ${ }^{58}-$. Sorprende asimismo encontrar en la carta algunos temas que el cardenal Montini consideraba importantes para la comunidad eclesial de aquel entonces y que luego descubriremos desarrollados con mayor claridad en su encíclica programática Ecclesiam suam y, en general, a lo largo de todo su pontificado. Nos referimos, en primer lugar, a la necesidad de una toma de conciencia eclesial - «el conocimiento íntimo de aquello que ella es y de aquello que ella debe hacer»-, aprovechando que «el Concilio ofrece a la Iglesia el espejo en el cual conocerse y contemplarse». De ahí debe brotar, como consecuencia natural, una «reforma de la vida eclesiástica», es decir, aquel «esfuerzo perenne en la Iglesia, que tiende a acercar la idea divina a la realidad humana, y ésta a aquélla», procurando ante todo «isu unión cada vez más estrecha con Cristo!». Y a ello se ha de sumar un valiente afán evangelizador, una búsqueda sincera y denodada "de entrar en contacto con el mundo», para lo cual la Iglesia «intentará hacerse hermana y madre de los hombres; intentará ser pobre, simple, humilde y amable en su lenguaje y en su vestimenta», sin olvidar a «los alejados», también "considerados y amados» ${ }^{59}$.

57 Cf. Concilio Vaticano II, Constitución dogmática Lumen gentium, 22.

58 Cf. ibid., 2-4.

59 G. B. Montini, Carta pastoral Pensiamo al Concilio, 22/2/1962, en DsC, 153 193; DSM III 4898-4935. Nuevamente Cipriano Calderón considera que «es éste el documento más importante y más valioso redactado por Pablo VI antes de su elección pontificia» (Calderón, "Semblanza de Pablo VI", 97). Se trata, en opinión del hoy Cardenal Giovanni Coppa, de un texto que «alcanza extraordinaria altura teológica y poética» (G. Coppa, "La meditazione su Roma di Giovanni Battista Montini", Notiziario dell'Istituto Paolo VI 20 [1990]: 64). Davide Marzaroli, por su parte, estima que «la carta pastoral [Pensemos en el Concilio] escrita para la arquidiócesis de Milán queda como uno de los testimonios más altos del desarrollo del pensamiento eclesiológico de Montini antes del Concilio y por esto, fundamental para entender el desarrollo sucesivo» (Marzaroli, 197, nota 6). Mientras que el P. Georges Cottier, futuro teólogo de la Casa Pontificia, opina que «el estudio de este gran texto me parece importante 
No son estos ciertamente, como decíamos, los únicos escritos montinianos sobre eclesiología ${ }^{60}$, pero bastan para mostrarnos la importancia que el misterio de la Iglesia tenía para él antes de ser elevado a la sede de Pedro y para revelarnos los acentos más importantes de su concepción de la Iglesia, como veremos a continuación.

\subsection{Principales RASgos DE SU APROXIMACIÓN ECLESIOLÓGICA}

La lectura de estos trabajos nos ha puesto ante una manera renovada de acercarse a la Iglesia, una mirada que, siendo fiel a la Tradición y bebiendo de sus fuentes, busca al mismo tiempo hacer más cercano y comprensible su misterio a los hombres y mujeres del nuevo siglo: «La Iglesia ha sido para nosotros una educación, casi inadvertida y connatural; es preciso que hoy se convierta para nosotros en ciencia y vida. Ha sido para nosotros una herencia del pasado; es preciso que se convierta en riqueza del presente. Ha sido para nosotros una tradición; es preciso que se convierta en conciencia y fuerza ${ }^{61}$. Lo que G. B. Montini quiere es recuperar el verdadero sentido de la Iglesia, esforzándose por mostrar que ella no es una asociación externa o extrínseca a los bautizados, una

para poner en evidencia las principales intuiciones eclesiológicas de G. B. Montini y para aclarar algunas ideas anticipatorias de su pontificado» (G. Cottier, Présentation a DsCon, 13).

${ }^{60}$ Además de los trabajos reseñados, pueden mencionarse, entre muchos otros: "La Chiesa: una", 15/1/1927, en SF, 68-70; "Chiesa docente", 5/1/1930, en SF, 355357; "La Iglesia y el alma consagrada", 1949, en ACD, 179-188; "Dilexit Ecclesiam", 30/8/1955, en DSM I 371-375; "La luce che irradia dalla Chiesa", 5/2/1957, en DSM I 1187-1190; "La promozione del laicato", 9/6/1957, en DSM I 1460-1470; "Il primato di Pietro", 1/11/1958, en DSM II 2405-2410; "Sant'Ambrogio e il suo amore alla Chiesa", 7/12/1958, en DsMS, 219-231; DSM II 2457-2466; "L'ufficio del vescovo", 11/1/1959, en DSM II 2533-2540; "Il segreto della Cattedrale", 26/4/1959, en DsC, 63-75; DSM II 2782-2793; "Fedeltà alla Chiesa", 31/7/1959, en DSM II 2938-2963; "La Chiesa è un Popolo vivo", 12/8/1959, en DSM II 2973-2983; "La Chiesa viva", 28/8/1960, en DSM II 3391-3397; "Il magistero della Chiesa in campo sociale", 18/11/1961, en DSM III 4735-4751; “Amare la Chiesa!”, 10/6/1962, en DSM III 5155-5163; “L'Eucaristia e la Chiesa", 2/9/1962, en DSM III 5260-5268; "La vocazione missionaria della Chiesa", 10/9/1962, en DSM III 5285-5300; "Sant'Ambrogio e il mistero della Chiesa", 7/12/1962, en DsMS, 273-281; "La Chiesa sta cercando se stessa”, 9/3/1963, en DSM III 5656-5661; “Amare Cristo e la Chiesa”, 7/4/1963, en DSM III 5707-5712; “L'origine della Chiesa”, 23/5/1963, en DSM III 5824-5831.

61 G. B. Montini, “La missione della Chiesa”, 9/10/1957, en $D s C, 18$. 
comunidad frente a la cual nos situamos, sino que «nosotros somos la Iglesia ${ }^{62}$.

Sensible a los signos de los tiempos y sirviéndose de los aportes que la renovación teológica había insuflado a la eclesiología, se propone igualmente superar la perspectiva juridicista y apologética que había caracterizado la época anterior. De ahí su insistencia en señalar que, más que una "sociedad perfecta» a semejanza de las instituciones humanas, «la Iglesia es un misterio que debe buscarse en la mente de Dios» ${ }^{63}$ - por ello "podríamos saber todo de la Iglesia, sin conocerla verdaderamente» ${ }^{64}$ - Y Y de ahí también el énfasis que pone en subrayar los vínculos cristológicos y pneumatológicos que sellan el origen y el ser de la comunidad eclesial.

En efecto, en la concepción montiniana de la Iglesia se descubre un marcado cristocentrismo, acento que ya era característico de todo su pensamiento, pero que se plasma de manera particular en su eclesiología $^{65}$. No se puede comprender a la Iglesia, es más, ni siquiera se puede justificar su existencia sin una referencia constante al Verbo Encarnado. Todo en ella remite a Cristo y a su Encarnación, al tiempo que cada una de sus dimensiones encuentra en Él su origen y justificación. La misma preocupación que tiene en subrayar que se trata de la «Iglesia de Cristo $»^{66} \mathrm{O}$ "Su Iglesia $»^{67}$ es ya indicativa de esta centralidad de Jesucristo en su concepción eclesial:

«No hagamos ahora una lección de teología sobre la Iglesia — afirma en uno de los muchos textos que podrían ser citados-. Nos basta recordar que Cristo es el fundador de la Iglesia; es Él quien la institu-

62 G. B. Montini, Carta pastoral Pensiamo al Concilio, 22/2/1962, n. 2c, en DsC, 156.

${ }^{63}$ Ibid., n. 25, 168; cf., además, n. 3, 157; n. 13, 164; n. 15, 164; nn. 24-33, 167-173.

${ }^{64}$ G. B. Montini, "Ciò che la Chiesa è e non è", 10/11/1960, en $D s C$, 119. Cf., además, $D s C$, 8-9, 118-120, 220-223.

65 «El principio teológico inspirador de la eclesiología montiniana es sin duda el cristocentrismo. La naturaleza y misión de la Iglesia sólo pueden ser comprendidas desde Cristo. [...] De los escritos e intervenciones de Pablo VI se deduce claramente que no cualquier eclesiología puede ser definida como tal. En todo caso para el Pontífice una eclesiología correcta no puede ser eclesiocéntrica, sino que ha de ser necesariamente cristocéntrica, en su magisterio se puede encontrar de modo claro y neto el paso teológico, casi epocal, del eclesiocentrismo al cristocentrismo» (Marzaroli, 198-199).

${ }_{66}$ Cf., p. ej., $D s C$, 13, 46, 79, 81, 83, 123, 126, 144, 156, 207, 213; RC-LC, 15.

67 Cf., p. ej., $D s C$, 10, 12, 72, 73, 80, 84, 98, 169, 201, 224, 235. 
ye, Él quien la genera, Él quien la envía. Es muy conocida la interpretación simbólica que los Padres le han dado a la herida al costado de Cristo crucificado, herida de la que manan sangre y agua. Como del costado de Adán durmiente Dios trajo a Eva, la madre de todos los vivientes, así del de Cristo, muerto por nosotros en la cruz, ha venido la Iglesia, madre de todos los creyentes (cf. S. Agustín, Tract., 120; Denz., 480).

Es necesario por ello comprender cómo la misión de Cristo se transfunde en la misión de la Iglesia» ${ }^{68}$.

Y esto se plasma, como decíamos, en cada una de sus realidades concretas:

«La Iglesia es la continuación de Cristo en el tiempo y la dilatación de Cristo en la tierra. Es su presencia viva. En la autoridad y en la enseñanza de la Iglesia, "quien os escucha, me escucha" (Lc 10,16). En la comunidad legítimamente constituida de la Iglesia, "donde hay dos o tres reunidos en mi nombre, allí estoy Yo en medio de ellos” (Mt 18,20). En la actividad y en la sucesión apostólica, presente para siempre, "he aquí, que estoy con vosotros - siempre es Cristo quien habla- todos los días hasta la consumación del tiempo" (Mt 28,20). Y el misterio del sacrificio eucarístico perpetuará esta inefable presencia de Jesús entre nosotros: "Cada vez que comáis este pan y bebáis de este cáliz, celebrararéis la muerte del Señor hasta que Él venga” (1Cor 11,26).

Es su acción salvadora. Esto es, el medio de su acción salvadora, el vehículo; instrumento en el ejercicio de la potestad de orden, es decir, en la administración de los Sacramentos, y colaboradora subordinada en el ejercicio de la potestad de jurisdicción, libre y humana causa segunda (Journet, L'Eglise, I, 132)» ${ }^{69}$.

En pocas palabras, «la Iglesia sabe ciertamente que no puede nada por sí misma, sino que todo lo recibe de Jesucristo, y despliega su acción porque Jesucristo está presente y actúa en ella. La Iglesia no es solamente la sociedad fundada por Cristo; es también su continuación y el instrumento a través del cual Él obra y realiza hoy la salvación del mundo» ${ }^{70}$.

${ }_{68}$ G. B. Montini, "La missione della Chiesa", 9/10/1957, en $D s C, 20-21$.

${ }_{69}$ G. B. Montini, Carta pastoral Pensiamo al Concilio, 22/2/1962, nn. 26-27, en DsC, $168-169$.

${ }^{70}$ G. B. Montini, "Intervención en la Congregación General XXXIV", 5/12/1962, 292. Cf., además, DsC, 10, 82; "Lettera al Cardinale Amleto Cicognani”, 18/10/1962, n. 2, Notiziario dell'Istituto Paolo VI 7 (1983), 12. 
Íntimamente unido a Cristo, y enviado por Él, se encuentra el Espíritu Santo, cuyo papel en la vida de la Iglesia es asimismo destacado por Giovanni Battista Montini: «El Espíritu Santo es enviado por Jesús como el animador de la Iglesia, y crea en ella la gracia, con sus carismas y sus dones ${ }^{71}$. No es posible, pues, aproximarse al misterio de la Iglesia, ni a ella se le podrían atribuir ninguna de sus notas - una, santa, católica y apostólica-, fijándose únicamente en los hombres que la componen, sin tener en cuenta la presencia vivificante del Espíritu, dado que ella no es una mera comunidad humana, sino un organismo «viviente de una animación del Espíritu Santo, del Espíritu que Jesús le infunde, que le otorga carismas y poderes, que la sostiene y la guía, que la anima y la rejuvenece, que la hace digna de ser llamada santa, única y universal ${ }^{72}$.

De esta concentración cristológica y pneumatológica brota naturalmente su visión teándrica de la Iglesia, en la que privilegia, además, la dimensión interior: «En efecto, ella es verdaderamente espiritual, sobrenatural, "pneumática", porque la parte más importante de ella, la parte esencial, principal de su ser, su alma, es del todo espiritual, del todo sobrenatural $\aleph^{73}$. Pero ello, evidentemente, sin olvidar o negar su dimensión exterior, como han pretendido algunos — sobre todo «los primeros reformadores» $\mathrm{y}$ «los protestantes liberales»-, sosteniendo «que la Iglesia no es una sociedad visible y jerárquica, sino sólo espiritual e invisible, sin cuidar que de tal modo se disolvía no sólo la Iglesia romana y católica, sino simplemente la Iglesia ${ }^{74}$. Así pues, alejándose de toda polarización o falsa oposición y buscando más bien una visión integral, presenta

«[...] los dos componentes fundamentales, que dan a la Iglesia su unidad viviente: el componente del elemento invisible, animador y divino, que decimos que es el pensamiento de Dios, su gracia, su asistencia; y el del elemento visible, es decir, la humanidad creyente y vivificada por la caridad, la "ecclesia sanctorum", la sociedad de los cristianos; podríamos decir, la composición del alma y del cuerpo, que hace de la Iglesia una entidad al mismo tiempo divina y humana, invisible en los dones que la hacen vivir, visible en los miembros que la componen, esto es, la continuación del misterio de la Encarnación $»^{75}$.

${ }^{71}$ G. B. Montini, Carta pastoral Pensiamo al Concilio, 22/2/1962, n. 27, en DsC, 169.

${ }^{72}$ G. B. Montini, "Ciò che la Chiesa è e non è", 10/11/1960, en DsC, 120. Cf., además, $D s C$, 10, 30, 49, 156 (n. 2b), 170 (n. 29), 174 (n. 35), 183 (n. 50), 223.

73 Ibid., 121.

${ }^{74}$ G. B. Montini, "Unità e Papato nella Chiesa", 29/8/1960, en DsC, 93.

75 Ibid., 85. 
Destaca asimismo en su aproximación al misterio de la Iglesia la visión que tiene de ella en clave de "comunión». No se trata de una sociedad fría o funcional, de un organismo anónimo o despersonalizado, tampoco de una agregación de individualidades, sino que, animada por el Espíritu Santo, «la Iglesia nos da una inserción en una comunión. La Iglesia es una familia universal. La Iglesia es una sociedad que vive en la fe y por la caridad. La Iglesia es un sistema de convergencia de relaciones que exaltan y salvan la vida humana ${ }^{76}$. Esto responde a la propia naturaleza humana, que encuentra en la comunidad la más grande gama de posibles grandezas y, en cambio, en el individualismo y el aislamiento, una fuente de empobrecimiento y debilidad. Y responde también al designio amoroso del Padre, que nos «ama a mí y a cada uno de nosotros en particular, pero ha querido que yo y cada uno de nosotros alcanzásemos la unión con Él a través de la unión entre nosotros y con los otros hermanos. Por eso existe la Iglesia ${ }^{77}$.

Esa unidad y esa comunión que se viven al interior del Cuerpo de Cristo no son para G. B. Montini, sin embargo, sinónimo de uniformidad. «Ella [la Iglesia] se nos presenta, bajo ciertos aspectos, como una comunidad de hermanos, todos iguales entre sí, y bajo ciertos otros, como una comunidad de pastores y de fieles, dotados los primeros de facultades específicas de santificación, de magisterio y de gobierno, que los otros no poseen ${ }^{78}$. Cada uno ha sido bendecido con unos dones particulares que debe poner al servicio de los demás, y cada uno posee también, de acuerdo a su vocación propia, unas responsabilidades que ha de observar para que el organismo en su conjunto pueda cumplir con su misión. Como enseña San Pablo en un pasaje que recoge el Arzobispo de Milán, «Él —Cristo- constituyó a unos apóstoles, a otros profetas, a otros evangelistas, a otros pastores y maestros [...] para la edificación del Cuerpo de Cristo» (Ef 4,11-12). Aquí se engarza el servicio jerárquico que prestan el Sumo Pontífice y los obispos en comunión con él, quienes conforman el «Colegio Episcopal» - por ello su interés en recalcar el «carácter colegial del Episcopado, en cuanto sucesor del Colegio Apostólico» ${ }^{79}$ - Y Y en este marco se comprende asimismo el papel que están

76 Ibid.

77 G. B. Montini, "La Chiesa nei suoi aspetti essenziali”, 1957, en $D s C$, 7.

78 G. B. Montini, "Unità e Papato nella Chiesa”, 29/8/1960, en DsC, 85-86.

79 G. B. Montini, Carta pastoral Pensiamo al Concilio, 22/2/1962, n. 22, en DsC, 167.

ESTUDIOS ECLESIÁSTICOS, vol. 94, núm. 370, septiembre 2019, 477-512, ISSN 0210-1610, ISSN-e 2605-5147 
llamados a desempeñar los laicos, de modo particular en este periodo de la historia, cuya identidad y cuya misión reciben tanta atención de su parte ${ }^{80}$.

Un puesto del todo singular en la comunión eclesial le corresponde en la concepción montiniana a la Virgen María, quien como Madre amorosa sigue intercediendo por cada uno de sus hijos:

«En la Iglesia nos encontramos en la casa del Padre; nos encontramos flanqueados y sostenidos por los hermanos, todos para cada uno y cada uno para todos; especialmente encontramos a la Madre, María Santísima. Ella no es sólo una bellísima figura histórica que nos ha dado a Jesús de una vez para siempre. Influye continuamente en el desarrollo espiritual de nosotros sus hijos, como una madre influye sobre la criatura que todavía guarda en su seno. Sin María, la Iglesia podría parecernos un organismo impersonal y frío; pero en cambio en la Iglesia está María, la Madre, que nos conoce y nos ama, y no es extraña al drama íntimo del más pequeño de sus hijos» ${ }^{81}$.

Por ello no duda en llamarla «Madre de Cristo y Madre de la Iglesia» ${ }^{82}$ o en considerarla como typus Ecclesiae ${ }^{83}$.

Todo ello, sin embargo, no se queda en una contemplación pasiva del Cuerpo de Cristo. La eclesiología montiniana es, por el contrario,

80 «Es también de esperar que el Laicado católico tendrá en el Concilio un reconocimiento explícito y honorífico. La persona del laico en la Iglesia será ciertamente exaltada al nivel al que la eleva el Bautismo, asumiéndolo a la vida sobrenatural, y la Confirmación, llamándolo a la profesión pública de su fe y a la perfección cristiana» (ibid., n. 45, 179). Cf. también $D s C$, 31-41, 148, 187 (n. 55).

${ }^{81}$ G. B. Montini, "La Chiesa nei suoi aspetti essenziali", 1957, en $D s C, 10$.

82 G. B. Montini, "Ciò che la Chiesa è e non è", 10/11/1960, en DsC, 127. Un par de años después, en su ya citada alocución en el aula conciliar comentando el esquema De Ecclesia, sostiene que "con aún mayor alegría acepto que la Bienaventurada Virgen María sea honrada como Madre de la Santa Iglesia por el Concilio» ("Intervención en la Congregación General XXXIV", 5/12/1962, 292). Y en la clausura de la tercera sesión conciliar, ya como pontífice, dirá: "Así pues, para gloria de la Bienaventurada Virgen y consuelo nuestro declaramos a María Santísima Madre de la Iglesia, es decir, de todo el pueblo cristiano, tanto de los fieles como de los Pastores, que la llaman Madre amadísima; y establecemos que de ahora en adelante con este título todo el pueblo cristiano tribute aún más honor a la Madre de Dios y le dirija súplicas» (Pablo VI, Discurso en la clausura de la tercera sesión del Concilio Vaticano II, 21/11/1964, 30).

${ }_{83}$ G. B. Montini, "La Chiesa nei suoi aspetti essenziali", 1957, en DsC, 6; cf. "Motivi e speranze della definizione dogmatica della Assunzione di Maria al cielo”, 1960, en DsMS, 56; DSM II 3713. 
eminentemente dinámica ${ }^{84}$, y tiene en la misión de la Iglesia —que, por lo demás, forma parte indisoluble de su misma esencia- uno de los polos de su atención. Y es que por la gracia del bautismo «todos pueden y deben asociarse a la acción apostólica de la Iglesia» ${ }^{85}$. Para poder cumplir fielmente con la misión que el Señor le ha encomendado, la Iglesia debe, en primer lugar, tomar "perfecta conciencia de sí misma»" ${ }^{86}$, lo que solo podrá lograr con «isu unión cada vez más estrecha con Cristo!, con el Cristo del Evangelio: su conocimiento, su imitación, su gracia» ${ }^{87}$. De ahí ha de brotar un afán de renovación interior, una continua e incansable reforma, que «es un esfuerzo perenne en la Iglesia, que tiende a acercar la idea divina a la realidad humana, y ésta a aquélla» ${ }^{88}$. Renovada y fortalecida, la Iglesia ha de salir en busca de todos los hombres, especialmente de los «alejados» ${ }^{89}$ y de «aquella vastísima y multiforme categoría de hermanos que son los cristianos, todavía adornados por tal nombre, pero separados de la unidad de la Iglesia Católica» ${ }^{90}$. De lo que

84 «La palabra "misión” que limita el inmenso campo en el que se extiende la doctrina de la Iglesia, recuerda a nuestro pensamiento esta figura de movimiento que caracteriza la vida de la Iglesia: ella parte de Cristo; por Él es enviada, impulsada, seguida; ella lo lleva consigo, lo predica, lo comunica, lo transmite; a través de ella, Cristo alcanza a los hombres, cruza las fronteras de las Naciones, sobrevuela los siglos, entra en contacto con la vida humana, sus formas, sus instituciones, sus costumbres, sus civilizaciones; sufre obstáculos, embestidas, persecuciones; encuentra fieles, conquistas, triunfos; y corre, sufriendo y creciendo, rezando y trabajando, enseñando y haciendo el bien; corre hacia un término que la atrae tanto, como si estuviera cerca; y la sostiene tanto, que no la hace conocer cansancio o decepción; corre, en la esperanza de un último día, en el que Cristo misterioso, al que lleva consigo, se le desvele y la absorba y la beatifique toda en sí; la vida eterna» (G. B. Montini, "La missione della Chiesa", 9/10/1957, en $D s C$, 19).

85 Ibid., 25.

${ }^{86}$ G. B. Montini, "Lettera al Cardinale Amleto Cicognani”, 18/10/1962, n. 4, Notiziario dell'Istituto Paolo VI 7 (1983), 13. Cf., además, DsC, 73-75, 104-105, 139 , $148,225$.

87 G. B. Montini, Carta pastoral Pensiamo al Concilio, 22/2/1962, n. 40, en DsC, 177.

${ }_{88}$ Ibid., n. 35, 174. Cf., además, $D s C$, 117, 173-176 (nn. 34-38), 213, 235-237.

89 Cf. G. B. Montini, "La carità della Chiesa verso i lontani", 1958, en DsC, 43-61.

90 G. B. Montini, Carta pastoral Pensiamo al Concilio, 22/2/1962, n. 58, en DsC, 188. Cf., además, $D s C$, 149-150, 188-191 (nn. 58-61), 213; "Pareri e voti per la buona riuscita del Concilio", 8/5/1960, Notiziario dell'Istituto Paolo VI 6 (1983): 42-43. Cf. también G. B. Montini - Paolo VI, L'Ottavario per l'unità dei cristiani. Documenti e discorsi (1955-1978) (Brescia: Istituto Paolo VI - Edizioni Studium, 1998). 
se trata, en fin, es de reabrir «el diálogo, un diálogo nuevo, con el mundo de la cultura y del arte, con la civilización redundante de medios e ignorante de fines $»^{91}$. En todas estas tareas, sin embargo, «la Iglesia no puede negar o minimizar la verdad, cuyo depósito inviolable se le ha encargado custodiar y difundir» ${ }^{92}$.

Son notables, por otra parte, su constante recurso a la Sagrada Escritura — casi exclusivamente a los libros del Nuevo Testamento-y sus abundantes referencias patrísticas, de manera particular a los Padres latinos — san Agustín de Hipona, san Ambrosio de Milán, san Cipriano de Cartago, san Gregorio Magno, san León Magno y san Beda-, pero también, aunque en menor medida, a los Apostólicos — san Ignacio de Antioquía- y a los griegos — san Juan Crisóstomo-.

En la misma línea debe subrayarse su perspectiva histórica, su mirada al pasado, no por un afán arqueológico, sino para aprender de él, en vistas a comprender mejor el presente y proyectarse con mayor fidelidad en el futuro. Ello brota, además, de la conciencia de que la Iglesia «está inserta en el tiempo y en la historia; trae consigo aquel hecho y aquel momento, que fue la misión redentora del Hombre-Dios en el mundo; pero se extiende, al mismo tiempo, hacia el futuro; se vuelve hacia el futuro regreso de Cristo glorioso; tiende a su destino escatológico, como se dice; vive del pasado, pero en el presente y para el futuro» ${ }^{93}$.

Finalmente, respecto a las categorías que utiliza para referirse a la comunidad eclesial, podemos anotar que tiene una clara preferencia por el término «más común de "Iglesia", que quiere decir convocación, y que ya "manifiesta la benignidad y el esplendor de la gracia divina y marca la distancia que separa a la Iglesia de las otras realidades temporales" (Journet, II, 50)» ${ }^{94}$. Se sirve asimismo con frecuencia de "Cuerpo (Místico) de Cristo», "la expresión paulina y clásica de la más sintética y más precisa definición de la Iglesia, [...] [y que] nos muestra "ante todo que la Iglesia es tanto espiritual como visible" ${ }^{95}$. Sobresalen también los tí-

91 G. B. Montini, "Unità e Papato nella Chiesa", 29/8/1960, en DsC, 96. Cf., además, $D s C$, 34, 151; $R C$ - $L C, 18,30$.

92 G. B. Montini, "La carità della Chiesa verso i lontani", 1958, en DsC, 52.

93 G. B. Montini, "Ciò che la Chiesa è e non è", 10/11/1960, en $D s C, 113$. Cf., además, DsC, 67, 105, 141-145, 201-207, 231-234.

94 Ibid., 122-123.

95 Ibid., 121. Cf., además, DsC, 27, 83, 87, 156, 184; id., Pasqua: la novità dell'amore (Milano: Centro Ambrosiano, 2010), 54-55, 96, 139-140, 154. 
tulos de «Madre $»^{96} \mathrm{y}$ «Maestra $»^{97}$, incluso antes de la aparición de la encíclica del papa Juan XXIII. Pero precisamente por ser un misterio que ningún concepto puede agotar y sabiendo que «sus nombres son un collar de gemas $»^{98}$, utiliza en sus escritos muchas otras categorías - como Esposa de Cristo, Pueblo de Dios, rebaño de Cristo, Jerusalén celestial, Reino, Ciudad, Casa de Dios, sacramento de Jesucristo, etc.-, expresiones que permiten, cada una con un matiz particular, ahondar en su naturaleza y misión.

Todos estos rasgos que distinguen la aproximación eclesiológica de G. B. Montini antes de acceder al solio pontificio y que acabamos de bosquejar se verán naturalmente prolongados y encontrarán su confirmación en su pontificado. Conviene notar que, si bien es preciso subrayar la asistencia particular que como pontífice recibe del Espíritu Santo en su misión de enseñar, continúan las líneas matrices de su pensamiento y mantienen validez las características que aquí hemos destacado.

\section{REFERENCIAS}

\section{Textos de G. B. Montini - San Pablo Vi}

Montini, G. B. "La Chiesa”. Studium 22 (1926): 583-587 y 23 (1927): 44$47,103-105$ y $162-170$.

96 «¿Por qué Madre? Penetrar en el sentido de esta denominación, referida a la Iglesia de Dios, significa en verdad volverla a comprender, significa amarla, significa reconocer su dignidad, su misión, su bondad, su necesidad. Madre, porque de la Iglesia recibimos la vida, la verdadera vida que es la sobrenatural, la que vencerá a la muerte y conquistará la plenitud. [...] Recordemos las célebres palabras de San Cipriano: "No podemos tener a Dios por padre si no tenemos a la Iglesia por madre" (Ep., 74,7). [...] Madre, porque es nuestra educadora. [...] Madre, porque nos ama como precisamente ama una madre, más que cualquier otro» (ibid., 124-125). Cf., además, $D s C$, 6, 33, 50, 103, 113, 212.

97 «Cristo es el Maestro. La Iglesia hablará, enseñará, repetirá su propia palabra. La Iglesia-Maestra. Su misión será la enseñanza, será custodiar, interpretar, pregonar la doctrina de Dios. Su misión será la escuela; sus misioneros, los catequistas, los maestros, los enseñantes, los profesores, los docentes, los predicadores, los Doctores, los Obispos, el Papa» (G. B. Montini, "La missione della Chiesa", 9/10/1957, en DsC, 33-34). Cf., además, $D s C, 6,113,115,123,212$.

98 G. B. Montini, "Ciò che la Chiesa è e non è", 10/11/1960, en $D s C, 122$. 
-. Introduzione allo studio di Cristo. Schemi di lezioni per studenti di scuole superiori. Roma: Editrice Studium, 1934.

- Note scolastiche per la storia della diplomazia pontificia. Roma: Edizioni Studium, 1934.

—. La "Responsio super Nunciaturis" di Papa Pio VI. Appunti delle lezioni del Sac. G. B. Montini per il corso di "Storia della Diplomazia Pontificia". Roma: Edizioni Studium, 1937.

- . "Discorso commemorativo tenuto in occasione del $250^{\circ}$ anniversario di fondazione della Pontificia Accademia Ecclesiastica nell'Aula magna della Cancelleria Apostolica", 25/4/1951. En La Pontificia Accademia Ecclesiastica, 1701-1951, XIII-XXIX. Città del Vaticano: Tipografia Poliglota Vaticana, 1951.

—. "L'aspetto religioso del pontificato di Pio XII", 27/2/1956. Notiziario dell'Istituto Paolo VI 17 (1988): 21-32.

-. "Considerazioni sul Magistero di S. S. Pio XII", 1956. Notiziario dell'Istituto Paolo VI 17 (1988): 32-40.

—. "Pareri e voti per la buona riuscita del Concilio", 8/5/1960. Notiziario dell'Istituto Paolo VI 6 (1983): 41-52; DSM II 3582-3588.

- . "Lettera del Cardinale Giovanni Battista Montini al Cardinale Amleto Cicognani, Segretario di Estado", 18/10/1962. Notiziario dell'Istituto Paolo VI 7 (1983): 11-14; DS III 5366-5370.

- . "Intervención en la Congregación General XXXIV sobre el esquema De Ecclesia", 5/12/1962. En Acta Synodalia Sacrosancti Concilii Oecumenici Vatican II, vol. I (Periodus Prima), pars IV (Congregationes Generales XXXI-XXXVI), 291-294. Civitas Vaticana: Typis Polyglottis Vaticanis, 1971,

—. Discorsi su La Chiesa (1957-1962). Milano: Arcivescovado di Milano, 1962.

- Roma e il Concilio - Lettere dal Concilio. Appendice al volume "La Chiesa". Milano: Arcivescovado di Milano, 1963.

—. Discorsi su la Madonna e su i santi (1955-1962). Milano: Arcivescovado di Milano, 1965.

—. Discorsi e scritti sul Concilio (1959-1963), Quaderni dell'Istituto Paolo VI 3. Brescia: Istituto Paolo VI - Edizioni Studium, 1983.

—. Lettere ai familiari. 1919-1943. Brescia: Istituto Paolo VI - Edizioni Studium, I-II, 1986.

—. Lettere a casa. 1915-1943. Milano: Rusconi, 1987. 
—. Discorsi e scritti milanesi (1954-1963), I. 1954-1957. II. 1958-1960. III. 1961-1963. IV. Appendice e Indici. Brescia: Istituto Paolo VI - Edizioni Studium, 1997-1998.

-. Scritti fucini (1925-1933), Quaderni dell'Istituto Paolo VI 24. Brescia: Istituto Paolo VI - Edizioni Studium, 2004.

-. La amistad con Dios. Meditaciones inéditas de G. B. Montini. Madrid: San Pablo, 2008.

-. Pasqua: la novità dell'amore. Omelie del triduo e scritti pasquali. Milano: Centro Ambrosiano, 2010.

-. Un'ora nuova nella storia. Discorsi e scritti dell'arcivescovo sul Concilio. Milano: Centro Ambrosiano, 2012.

Montini, G. B. - Paolo VI. L'Ottavario per l'unità dei cristiani. Documenti e discorsi (1955-1978), Quaderni dell'Istituto Paolo VI 18. Brescia: Istituto Paolo VI - Edizioni Studium, 1998.

Pablo VI, San. Discurso a la benemérita familia de "Studium», 10/2/1964.

- Discurso en la clausura de la tercera sesión del Concilio Vaticano II, 21/11/1964.

-. Discurso al Presidente de Francia, 31/5/1967.

-. Discurso a los miembros del Episcopado Suizo, 10/6/1969.

-. Telegrama al Prior de los Pequeños Hermanos de Jesús, 29/4/1973.

-. Meditación a la hora del Angelus, 29/4/1973.

- Carta apostólica Lumen Ecclesiae, 5/12/1974.

-. Telegrama al Presidente de la Conferencia Episcopal Suiza, 16/4/1975.

—. "Pablo VI al R.P. Henri de Lubac, S. J. Nota introductoria del Cardenal Villot". Stromata 33 (1977): 127-128.

-. Su l'arte e agli artisti. Discorsi, messaggi e scritti (1963-1978). Brescia: Istituto Paolo VI - Edizioni Studium, 2000.

Roncalli, A. G. - Montini, G. B. Lettere di fede e amicizia (1925-1963). Brescia: Istituto Paolo VI - Edizioni Studium, 2013.

2. OtROS LIBROS Y ARTí́cULOS

Adornato, G. Pablo VI. El coraje de la modernidad. Madrid: San Pablo, 2010.

Boissard, G. "La relation Montini-Journet". En Istituto Paolo VI, Montini, Journet, Maritain: une famille d'esprit. Journées d'étude (Molsheim, 4-5 juin 1999), 10-47. Brescia: Istituto Paolo VI - Edizioni Studium, 2000 . 
Brambilla, F. G. "Carlo Colombo e G. B. Montini alle sorgenti del Concilio”. La Scuola Cattolica 130 (2002): 221-260.

- . "La ricerca faticosa di una via per il Concilio: Giovanni XXIII e Montini-Paolo VI". Teologia 37 (2012): 335-360.

Bressan, L., y Maffeis, A., eds. Montini, Arcivescovo di Milano. Brescia: Istituto Paolo VI - Edizioni Studium, 2016.

Calderón, C. Montini, Papa. Salamanca: Ediciones Sígueme, 1963.

- . "El estudio de los temas eclesiales apasionó a Pablo VI desde su juventud”. Hechos y dichos 42 (1965): 652-655.

-. "Semblanza de Pablo VI". En Instituto Social León XIII, El diálogo según la mente de Pablo VI. Comentarios a la "Ecclesiam Suam", 81108. Madrid: BAC, 1965.

Campanini, G. “Montini e Maritain”. Studium 80 (1984): 349-358.

Caprile, G. "Aspetti positivi della terza sessione del Concilio". La Civiltà Cattolica 116/I (1965): 317-341.

Chenaux, Ph. Paul VI et Maritain. Les rapports du "montinianisme" et du "maritanisme". Brescia: Istituto Paolo VI - Edizioni Studium, 1984.

—, ed. Giovanni XXIII e Paolo VI. I due Papi del Concilio. Roma: Lateran University Press, 2013.

Colombo, G. "Genesi, storia e significato dell'enciclica "Ecclesiam Suam»". En Istituto Paolo VI, "Ecclesiam Suam», première lettre encyclique de Paul VI. Colloque International (Rome, 24-26 octobre 1980), 131-177. Brescia: Edizioni Studium, 1982.

Congar, Y. "Situation ecclésiologique au moment de «Ecclesiam Suam»". En Istituto Paolo VI, "Ecclesiam Suam», première lettre encyclique de Paul VI. Colloque International (Rome, 24-26 octobre 1980), 79-102. Brescia: Edizioni Studium, 1982.

Concilio Vaticano II. Constitución dogmática Lumen gentium.

Coppa, G. "La meditazione su Roma di Giovanni Battista Montini". Notiziario dell'Istituto Paolo VI 20 (1990): 57-70.

Cottier, G. Présentation a Montini, G. B., Discorsi e scritti sul Concilio (1959-1963). Quaderni dell'Istituto Paolo VI 3, 5-15. Brescia: Istituto Paolo VI - Edizioni Studium, 1983.

Crivelli, L. Montini Arcivescovo a Milano. Un singolare apprendistato. Milano: San Paolo, 2002.

Díaz, G., y S. Miscioscia. Pablo VI cita a San Agustín. Apuntes del Papa Montini (1954-1978). Madrid: Ediciones Escurialenses, 2004.

Dorn, L. A. Pablo VI. El reformador solitario. Barcelona: Herder, 1990. 
Fornasari, E. "Mi Cardenal", 1963. En Encuentros con Pablo VI, J. L. González. Bilbao: Paulinas, 1968.

Grootaers, J. "L'attitude de l'archevêque Montini au cours de la première pèriode du Concile (octobre 1962-juin 1963)”. En Istituto Paolo VI, Giovanni Battista Montini, Arcivescovo di Milano e il Concilio Ecumenico Vaticano II. Preparazione e primo periodo. Colloquio Internazionale di Studio (Milano, 23-25 di settembre di 1983), 256-286. Brescia: Edizioni Studium, 1985.

Guasco, M. "La formazione sacerdotale di Giovanni Battista Montini". En Istituto Paolo VI, El sacerdocio en la obra y el pensamiento de Pablo VI. Giornata di studio (Salamanca, 8 di novembre di 1991), 126133. Brescia: Edizioni Studium, 1994.

Guitton, J. Diálogos con Pablo VI. Madrid: Ediciones Cristiandad, 1967.

-. Paolo VI segreto. Milano: San Paolo, 1985.

Hera, E. de la. La noche transfigurada. Biografía de Pablo VI. Madrid: BAC, 2002.

Istituto Paolo VI. Paul VI et l'art. Journée d'études (Paris 27 janvier 1988). Brescia: Edizioni Studium, 1989.

-. Montini, Journet, Maritain: une famille d'esprit. Journées d'étude (Molsheim, 4-5 juin 1999). Brescia: Istituto Paolo VI - Edizioni Studium, 2000.

Lanza, F. "Paolo VI e la letteratura". Otto/Novecento 1 (1979): 5-42.

-. Paolo VI e gli scrittori. Brescia: Istituto Paolo VI - Edizioni Studium, 1994.

Levi, V., ed. Il Gesù di Paolo VI. Milano: Mondadori, 1985.

Lubac, H. de. Memoria en torno a mis escritos. Madrid: Ediciones Encuentro, 2000.

Macchi, P. "Discussion”, 26/10/1980. En Istituto Paolo VI, "Ecclesiam Suam», première lettre encyclique de Paul VI. Colloque International (Rome, 24-26 octobre 1980), 178-244. Brescia: Studium, 1982.

Manziana, C. "La formation liturgique de G. B. Montini". En Istituto Paolo VI, Le rôle de G. B. Montini-Paul VI dans la réforme liturgique. Journée d'Études (Louvain-la Neuve, 17 octobre 1984), 23-31. Brescia: Edizioni Studium, 1987.

Marchetto, A. "Fu monsignor Giovanni Battista Montini uno storico?". Apollinaris 62 (1989): 243-252.

Martina, G. "Paolo VI e la ripresa del Concilio". En Istituto Paolo VI, Paolo VI e i problemi ecclesiologici al Concilio. Colloquio Internazionale 
di Studio (Brescia, 19-21 di settembre di 1986), 19-55. Brescia: Edizioni Studium, 1989.

- . "El contexto histórico en el que nació la idea de un nuevo Concilio ecuménico". En Vaticano II: balance y perspectivas. Veinticinco años después (1962-1987), editado por R. Latourelle, 25-64, 2a ed. Salamanca: Ediciones Sígueme, 1990.

Marzaroli, D. "Pablo VI, artífice y exegeta de la eclesiología postconciliar". Ecclesia. Revista de cultura católica 2 (1997): 195-218.

Molinari, F. "Il Gesù del giovane Montini”. Studium 77 (1981): 675-688.

—. "Le letture del giovane Montini (Storia della Chiesa e dintorni)". En G. B. Montini e la società italiana, 1919-1939, G. Campanini, et al., 5982. Brescia: CeDoc, 1983.

Morerod, Ch. "Montini et l'ecclésiologie de Journet". En Istituto Paolo VI, Montini, Journet, Maritain: une famille d'esprit. Journées d'étude (Molsheim, 4-5 juin 1999), 140-171. Brescia: Istituto Paolo VI - Edizioni Studium, 2000.

Mougel, R. "Maritain, Paul VI et l'Église du Concile". Notiziario dell'Istituto Paolo VI 39 (2000): 82-100.

Peri, V. “Appunti per un'indagine sull'ecclesiologia di Paolo VI. Titoli di originalità dell' "Ecclesiam Suam»". Rivista di Storia e Letteratura Religiosa 17 (1981): 409-450.

Pontiggia, V. "Le fonti giovanili del pensiero di Paolo VI sulla liturgia". Notitiae 24 (1988): 543-565.

Possenti, V. "Presenza di Tomasso d'Aquino in Giovanni Battista Montini”. Studium 95 (1999): 365-378.

Poupard, P. "Paolo VI: la sua cultura, la sua fede". Notiziario dell'Istituto Paolo VI 23 (1992): 17-23.

Prévotat, J. "Les sources françaises dans la formation intellectuelle de G. B. Montini". En Paul VI et la modernité dans l'Église. Actes du Colloque organisé par l'École Française de Rome (Rome, 2-4 juin 1983) avec le concours de l'Istituto Paolo VI de Brescia, 101-127. Roma: École Française de Rome, 1984.

Rossi, R. 'G. B. Montini alla 'Sapienza'. Note di storia religiosa del Risorgimento". Notiziario dell'Istituto Paolo VI 41 (2001): 7-29.

Rumi, G. "Il senso della storia in Paolo VI", en Istituto Paolo VI, Educazione, intellettuali e società in G. B. Montini-Paolo VI. Gionate di Studio (Milano, 16-17 di novembre di 1990), 118-129. Brescia: Studium, 1992. 
Torrel, J.-P. "Paul VI et le Cardinal Journet. Aux sources d'une ecclésiologie”. Notiziario dell'Istituto Paolo VI 13 (1986): 57-68.

Trebeschi, M. "Il pensiero teologico del giovane Montini: la liturgia". Brixia sacra. Memorie storiche della diocesi di Brescia 1-2-3-4 (1986): 107-130.

Viotto, P., ed. "S. Tommaso e l'anima giovanile studentesca". Notiziario dell'Istituto Paolo VI 44 (2002): 7-25.

Toscani, X., ed. Paolo VI. Una biografia. Brescia: Istituto Paolo VI - Edizioni Studium, 2014. 